\title{
DinÂMICA OSCILATÓRIA NA ELETROOXIDAÇÃO DE
}

\section{ETILENO GLicOL}

Dissertação apresentada ao Instituto de Química de São Carlos para obtenção do título de mestre em ciências (Físico-Química).

ORIENTADOR: PROF. DR. HAMILTON VARELA

SÃO CARLOS

2007 


\section{AgRADECIMENTOS}

A Deus por me propiciar vida e saúde;

Ao Prof. Hamilton pela boa orientação e pela amizade durante esse dois anos de convivência;

À minha família por sempre me acolher nos bons (e nem tão bons) momentos;

Aos colegas de grupo André, Adriano, Bruno, Gustavo, Hyrla, Melke, Paulo, Raphael e Roberto pela boa convivência no laboratório;

Aos colegas do grupo de eletroquímica;

Aos funcionários e técnicos do IQSC que contribuíram (cada um a sua maneira) para o desenvolvimento desse trabalho;

Aos amigos de happy hour: Cristian, Gisele, Graciele, Julianas (Paganelli e Romano), Marcello, Mariana, Melissa, Rafael, Thiago e em especial à Ana pelos momentos em que é preciso escapar da realidade e esquecer um pouco dos problemas;

Ao CNPq e à FAPESP (processo 06/01088-5) pelo apoio financeiro. 


\section{SUMÁRIO}

LISTA DE FIGURAS ...................................................................................................................................... IV

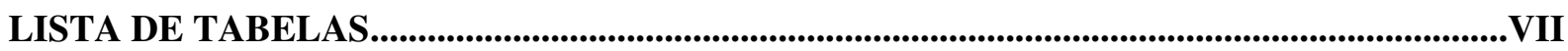

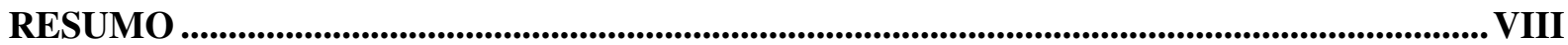

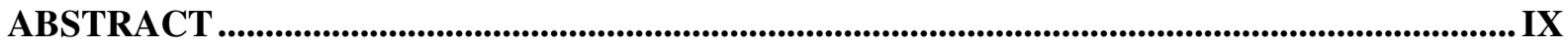

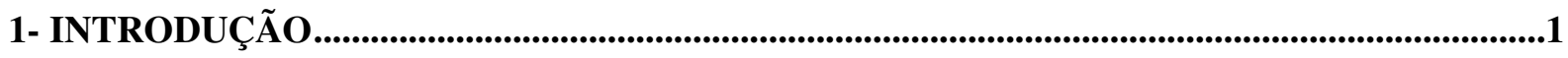

1.1 - Instabilidades Dinâmicas .............................................................................................1

1.2 - Eletrooxidação de Etileno Glicol..................................................................................

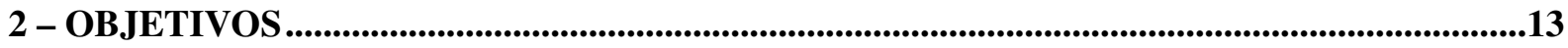

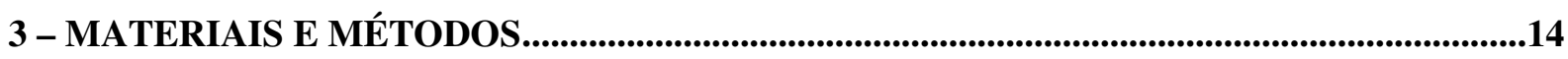

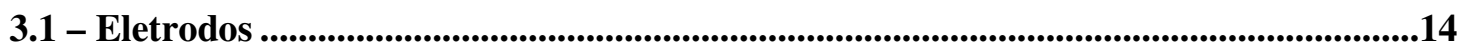

3.2 - Reagentes ..................................................................................................................................15

3.3 - Instrumentação...........................................................................................................................16

3.4 - Procedimentos Pré-Experimentais ...............................................................................................16

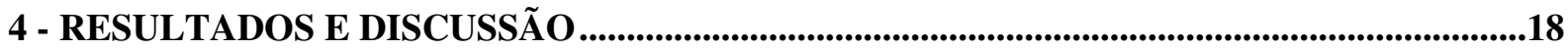

4.1 - Espectroscopia de Impedância Eletroquímica ..........................................................................18

4.2 - Oscilações em Modo Potenciostático...........................................................................................20

4.3 - Oscilações em Modo Galvanostático .................................................................................................23

4.3.1 - A Influência da Concentração.........................................................................24

4.3.2 - Influência da Densidade de Corrente ...............................................................................36

4.3.3 - Influência dos Intermediários de Reação ........................................................................40

4.4 - Análise Geral do Processo Oscilatório ..........................................................................50

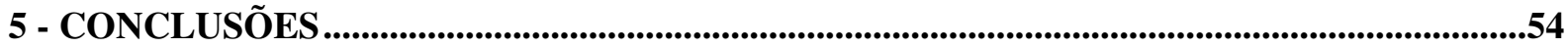

6 - PERSPECTIVAS .......................................................................................................................55

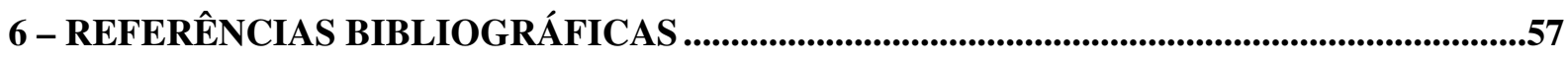




\section{LISTA DE FIGURAS}

Figura 1 - Representação esquemática do eletrodo de trabalho e as resistências a ele acopladas. $R_{\text {ext }}=$ resistência externa; $R_{\text {sol }}=$ resistência da solução, $C_{D}$ capacitância da dupla camada; $Z_{F}=$ impedância faradaica; $\varphi=$ potencial sem queda ôhmica e WE eletrodo de trabalho

Figura 2 - Variação dos perfis de (a) I vs U com o aumento de $\mathrm{R}_{\text {ext }}$, quando mais escura a cor, maior $\mathrm{R}_{\mathrm{ext}} \mathrm{e}$ (b) perfil de I vs $\mathrm{U}$ quando a $\mathrm{R}_{\mathrm{ext}}$ é alto suficiente para tornar o sistema instável.

Figura 3 - Produtos de oxidação parcial do etileno glicol em meio alcalino

Figura 4 - Voltamograma cíclico (ao centro) obtido durante a eletrooxidação de EG $(0,4 \mathrm{M}) \mathrm{em} \mathrm{KOH}(1 \mathrm{M})$ sobre platina. $\mathrm{v}=10 \mathrm{mV} . \mathrm{s}^{-1}$. Nas bordas, são mostrados os diagramas de impedância.

Figura 5 - Séries temporais obtidas sob controle potenciostático com $\mathrm{U}=2 \mathrm{~V}$ e $\mathrm{R}=$ $200 \Omega$. Cronoamperometria em 0,1 M de $\mathrm{KOH}$ e 0,4 M de EG, mostrando a região onde o sistema oscila (a) e os diferentes padrões encontrados (b-d).

Figura 6 - Diagrama de bifurcação no plano $U$ vs $R_{\text {ext }}$ mostrando parte da região onde o sistema apresenta comportamento oscilatório (círculos fechados) e onde o sistema não apresenta comportamento oscilatório (círculos abertos).

Figura 7 - Cronopotenciometria em solução $0,1 \mathrm{M}$ de $\mathrm{KOH} 0,1 \mathrm{M}$ e 0,4 M de EG mostrando a região onde o sistema oscila (a) e os diferentes padrões encontrados (b-d).

Figura 8 - Perfis de oscilação de potencial sob regime galvanodinâmico no sistema metanol (0,68 M), $\mathrm{H}_{2} \mathrm{SO}_{4}(0,49 \mathrm{M})$ e ácido fórmico $0,1 \mathrm{M}, \mathrm{H}_{2} \mathrm{SO}_{4} 0,5 \mathrm{M}$.

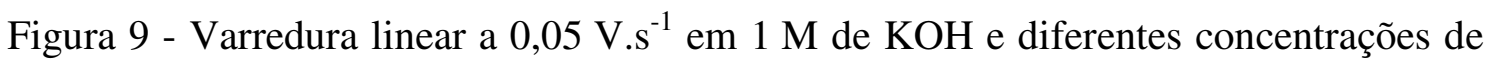
EG. 
Figura 10 - (a) o atrator gerado pelo atraso $\tau$; (b) seção de Poincaré $E(t+\tau)=E(t+2 \tau)$; (c) intersecção do atrator com a seção de Poincaré e (d) mapa unidimensional construído através da seção de Poincaré.

Figura 11- (a) padrões de oscilação encontrados em regime galvanostático (lado esquerdo) e correspondentes mapas de Lorenz (lado direito). (b) Perfil geral do potencial em função do tempo e proporção em que cada padrão operou. $\mathrm{j}=$ 3,4 mA.cm ${ }^{-2}$ Soluções: $1 \mathrm{M}$ de KOH e 0,15 M de EG.

Figura 12 - (a) Padrões de oscilação encontrados em regime galvanostático e os correspondentes mapas de Lorenz (sempre a direita do gráfico correspondente) e (b) Perfil geral do potencial em função do tempo e proporção em que cada padrão operou. j= 3,4 mA.cm ${ }^{-2}$ Soluções: $1 \mathrm{M}$ de $\mathrm{KOH}$ e 0,4 M de EG.

Figura 13 - Atratores em 2 dimensões gerados a partir dos padrões de períodos 2, 3 e caótico.

Figura 14 - (a) Padrões de oscilação encontrados em regime galvanostático e os correspondentes mapas de Lorenz e (b) Perfil geral do potencial em função do tempo e proporção em que cada padrão operou. $\mathrm{j}=3,4 \mathrm{~mA} \cdot \mathrm{cm}^{-2}$ Soluções: $1 \mathrm{M}$ de $\mathrm{KOH}$ e $0,8 \mathrm{M}$ de EG.

Figura 15 - (a) Padrões de oscilação encontrados em regime galvanostático e os correspondentes mapas de Lorenz e (b) Perfil geral do potencial em função do tempo e proporção em que cada padrão operou. $\mathrm{j}=3,4 \mathrm{~mA} \cdot \mathrm{cm}^{-2}$ Soluções: $1 \mathrm{M}$ de $\mathrm{KOH}$ e 1,6 M de EG.

Figura 16 - Influência da densidade de corrente durante medidas de cronoamperometria.

No detalhe as 5 últimas adições.

Figura 17 - Tempo de indução em função da densidade de corrente aplicada.

Figura 18 - Relação percentual dos padrões de oscilação sob regime galvanostático em diferentes correntes. $1 \mathrm{M} \mathrm{KOH}+0,4 \mathrm{M}$ EG.

Figura 19 - Porcentagens dos padrões apresentados em função da corrente aplicada. 40 
Figura 20 - Voltamograma cíclico a 0,05 V.s ${ }^{-1}$ em 1 M de KOH (preto), após adição de 0,4 M de EG (vermelho) e após adição de 44 mM de GA (verde).

Figura 21 - Influência da quantidade de glicolaldeído durante medidas de cronoamperometria. $\mathrm{j}=3,4 \mathrm{~mA} \cdot \mathrm{cm}^{-2}$

Figura 22 - Voltamograma cíclico a 0,05 V.s ${ }^{-1}$ em 1 M de KOH (preto), após adição de 0,4 M de EG (vermelho) e após adição de 0,7 M de AG (verde).

Figura 23 - Influência da quantidade de ácido glicólico durante medidas de cronoamperometria. $\mathrm{j}=3,4 \mathrm{~mA} \cdot \mathrm{cm}^{-2}$. No detalhe as 5 últimas adições.

Figura 24 - Voltamograma cíclico a 0,05 V.s ${ }^{-1}$ em 1 M KOH (preto), após adição de 0,5 $\mathrm{M}$ de AG (vermelho).

Figura 25 - Cronoamperometria a $0,8 \mathrm{~V}$ com várias adições de AG. A curva (0) corresponde ao sistema contendo $1 \mathrm{M}$ de $\mathrm{KOH}+0,4 \mathrm{M}$ de $\mathrm{EG}$.

Figura 26 - Carga normalizada obtida sob regime potenciostático em função da concentração de AG

Figura 27 - Carga normalizada obtida em regime galvanostático considerando apenas o período de indução (círculos abertos) ou todo o processo (quadrados fechados) em função da concentração de AG.

Figura 28 - Relação entre as cargas normalizadas obtidas sob regime galvanostático potenciostáticos em várias concentrações de AG.

Figura 29 - Ilustração dos ciclos de retro-alimentação positivo e negativo após uma perturbação para um sistema com impedância faradaica negativa e uma espécie química Y.

Figura 30 - (a) Espectros de FTIR coletados em função do tempo durante a eletrooxidação de metanol. (b) recobrimento de CO obtido através da integração da banda em $2069 \mathrm{~cm}^{-1}$ e (c) evolução do potencial no tempo, para $\mathrm{t}<0$ o eletrodo estava polarizado em $0,05 \mathrm{~V}$, para $\mathrm{t}>0$ uma corrente de $1,1 \mathrm{~mA} . \mathrm{cm}^{-2}$ foi aplicada. ......56 


\section{LISTA DE TABELAS}

Tabela 1 - Exemplos de sistemas oscilantes com pequenas moléculas orgânicas .7 


\section{RESUMO}

No presente trabalho foram estudados alguns aspectos não lineares da catálise da oxidação de etileno glicol (EG) sob platina em meio alcalino $(\mathrm{KOH})$. A dinâmica do sistema foi investigada através de voltametria cíclica, séries temporais de corrente e potencial e por espectroscopia de impedância eletroquímica. (EIE). Os resultados da EIE revelaram a presença de uma região de resistência diferencial negativa escondida nas proximidades o pico principal obtido na voltametria cíclica. De modo geral o sistema se mostrou apto a oscilar tanto sob regime potenciostático quanto galvanostático e por longos períodos de tempo apresentando uma miríade de estados dinâmicos que incluem oscilações harmônicas, de baixa e alta amplitudes, períodos 2, 3, 4 e modos mistos, além da duplicação de período na transição para o caos. A concentração tanto de EG como de $\mathrm{KOH}$ tiveram caráter essencial nos padrões temporais observados. A complexidade dos períodos aumenta com o aumento da concentração de EG resultando em $90 \%$ do tempo em que o sistema passa oscilando devotado às oscilações caóticas quando a concentração de EG é de 1,6 M. O aumento da densidade de corrente produz um efeito contrário nos padrões, ou seja, quanto mais alta é a corrente mais simples são os períodos. A influência de alguns produtos de oxidação parcial do EG foi estudada em diferentes condições. Os resultados das mudanças de morfologia das oscilações são racionalizados em termos das eventuais conexões com os intermediários de reação formados durante o processo de oxidação que, por sua vez, dependem da concentração do álcool e da densidade de corrente. 


\begin{abstract}
In the present work were studied some nonlinear aspects of the catalytic oxidation of ethylene glycol (EG) on platinum electrodes in alkaline media $(\mathrm{KOH})$. The system's dynamics was investigated by means of cyclic voltammetry, current and potential time series, and electrochemical impedance spectroscopy (EIS). The EIS results reveal the presence of a hidden negative differential resistance around the main voltammetric peak. Overall, the system was able to oscillate for several periods, displaying a myriad of dynamic states which includes harmonic, small and large amplitude, periods 2, 3, and 4, and mixed-mode oscillations, as well as period doubling transition to chaos. The concentration of both EG and $\mathrm{KOH}$ were found to play an essential role in the temporal patterns observed. The complexity of the periods increase with EG concentration resulting in $90 \%$ of the oscillating time devoted to chaotic patters when EG concentration is $1.6 \mathrm{M}$. The increment of the current density produces an opposite behavior of the patters: the higher the applied current the simpler the oscillatory dynamics. The influence of some products of partial EG oxidation was studied under different conditions and compared. The results of the changes in the oscillatory morphology are rationalized in terms of its eventual connection with reaction intermediates formed during the oxidation process that, in turn, depends on the alcohol concentration and on the current density.
\end{abstract}




\section{1- INTRODUÇão}

$\mathrm{O}$ entendimento dos processos relacionados às propriedades emergentes em sistemas complexos depende diretamente (a) da dinâmica temporal de elementos reacionais simples, e (b) das interações ou formas de acoplamento entre esses elementos. A emergência espontânea de padrões espaço-temporais em sistemas afastados do estado de equilíbrio termodinâmico tem se tornado uma área de pesquisa de crescente interesse nas últimas duas décadas. De caráter interdisciplinar, há exemplos de estudos em diversos campos incluindo química, física, biologia, ciência dos materiais e geologia [1,2]. Exemplos físico-químicos são encontrados em sistemas homogêneos como na celebrada reação de Belousov-Zhabotinsky [3] e heterogêneos, tanto na interface sólido/gás [4] quanto na interface sólido/líquido [5-8]

\section{1 - INSTABILIDADES DINÂMICAS}

A grande maioria dos processos que ocorrem na interface eletrodo/solução pode, a princípio, apresentar instabilidades dinâmicas em uma certa faixa de parâmetros experimentais [5-8]. Cinética complexa em sistemas eletroquímicos está primariamente relacionada à presença de auto-catálise no potencial do eletrodo, expressa na forma de uma região de resistência diferencial negativa (negative differential resistance, NDR) na curva estacionária de corrente-potencial [9,10]. Nesse sentido, reações eletrocatalíticas são especialmente susceptíveis a instabilidades dinâmicas graças à presença comum de competição por sítios ativos entre diferentes espécies e a conseqüente dependência no 
potencial das suas respectivas isotermas de adsorção [11-13]. Tem sido postulado que a eletrooxidação moléculas orgânicas pequenas, principalmente sobre superfícies à base de platina, procede segundo um mecanismo paralelo conhecido como dual [14] que envolve: (a) a via direta e ocorre através da formação de intermediários ativos que, uma vez formados, são rapidamente oxidados ao produto final $\mathrm{CO}_{2}$; e (b) a via indireta na qual $\mathrm{CO}$ adsorvido bloqueia a superfície e só é removido a altos potenciais através da reação com espécies oxigenadas como $\mathrm{OH}$.

Assim, a partir das similaridades mecanísticas postula-se usualmente que as instabilidades dinâmicas resultantes nesses sistemas pertencem à classe dos osciladores eletroquímicos do tipo HN-NDR [13]. Tal nomenclatura é associada à presença de uma resistência diferencial negativa em uma curva de polarização em forma de "N" parcialmente escondida (hidden, H) em condições voltamétricas. Mecanisticamente, os ciclos de retroalimentação envolvidos na dinâmica oscilatória estão relacionados à interação entre as isotermas de adsorção dependentes do potencial das espécies bloqueantes que envenenam a reação de fundo [13].

Indiscutivelmente, a característica mais marcante dos osciladores eletroquímicos do tipo HN-NDR é a propriedade de oscilarem tanto sob controle galvanostático quanto potenciostático quando a resistência em série entre o eletrodo de trabalho e o potenciostato (incluindo a resistência da solução) excede um certo valor crítico. Tal requerimento se deve tão somente à liberdade requerida ao potencial no plano reacional do eletrodo de trabalho, $\varphi$, de oscilar, assegurada pela queda ôhmica em série com o eletrodo de trabalho. Considerando a voltagem $U$ aplicada entre os eletrodos de trabalho e referência, a relação entre U e $\varphi$ é dada por: $U=\varphi+I R$ [10]. Nessa relação, $R$ representa a soma das resistências da solução, $R_{\text {sol }}$, e externa conectada em série entre o eletrodo de trabalho e potenciostato, $R_{\text {ext }}$. A Figura 1 mostra um esquema do eletrodo de trabalho (WE) e as resistências envolvidas. O eletrodo de 
trabalho pode ser descrito como a conexão em paralelo entre um capacitor $\left(\mathrm{C}_{\mathrm{D}}\right)$ devido à capacitância da dupla camada e um componente contendo uma impedância faradaica $\left(Z_{\mathrm{F}}\right)$ que corresponde a todos os processos faradaicos que estarão ocorrendo no eletrodo. O potencial $\varphi$ é determinado entre as conexões de $\mathrm{C}_{\mathrm{D}}$ e $\mathrm{Z}_{\mathrm{F}}$ e o potencial $\mathrm{U}$ engloba também as quedas de potencial nas resistências em série.

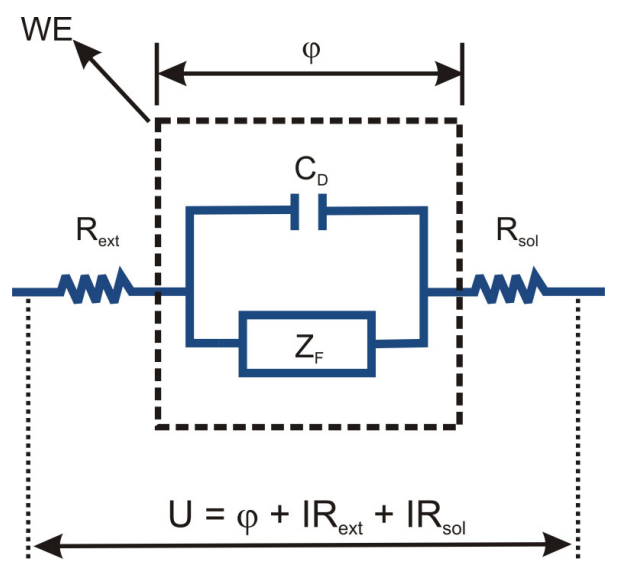

Figura 1 - Representação esquemática do eletrodo de trabalho e as resistências a ele acopladas. $R_{\text {ext }}=$ resistência externa; $R_{\text {sol }}=$ resistência da solução, $C_{D}$ capacitância da dupla camada; $Z_{\mathrm{F}}=$ impedância faradaica; $\varphi=$ potencial sem queda ôhmica e WE eletrodo de trabalho.

Em condições potenciostáticas para que ocorra oscilações a resistência $\mathrm{R}$ tem que exceder um certo valor crítico, a Figura 2 mostra como $U$ é influenciado pelo aumento da resistência. 


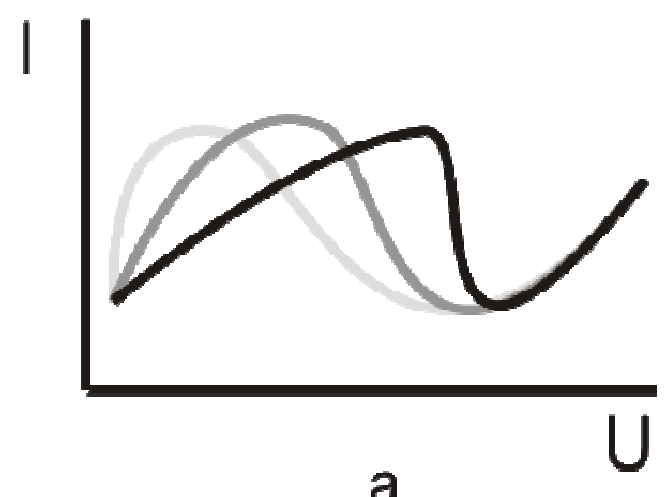

a

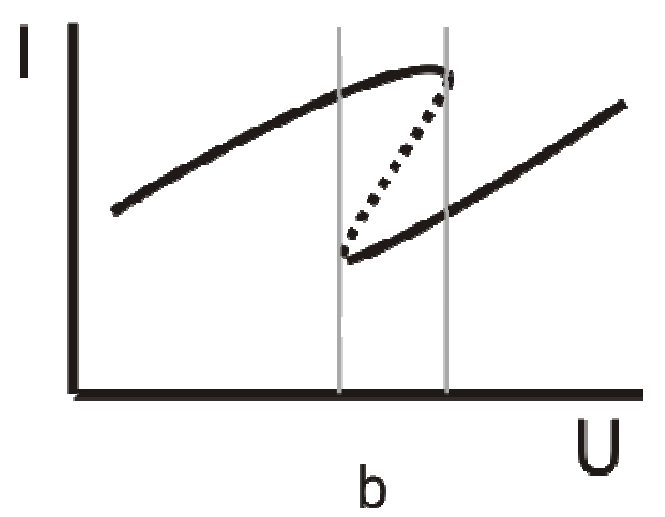

Figura 2 - Variação dos perfis de (a) I vs U com o aumento de $\mathrm{R}_{\text {ext }}$, quando mais escura a cor, maior $R_{\text {ext }}$ e (b) perfil de I vs $U$ quando a $R_{\text {ext }}$ é alto suficiente para tornar o sistema instável.

À medida que R aumenta, a curva I vs $\mathrm{U}$ vai se tornado cada vez mais perpendicular na região onde a corrente diminui com o aumento de potencial, até o ponto onde cria-se uma região não acessível de potencial, como mostrado no lado (b) da figura, assim a curva deixa de ser continua e nas proximidades daquele ponto uma pequena variação de U pode gerar um grande mudança de I.

Analisando o desenho da Figura 1 e aplicando a lei de Kirchhoff (também conhecida como lei das malhas ou dos nós) tem-se que a corrente total que circula no eletrodo de trabalho é a soma do braço capacitivo e do braço da impedância faradaica $\mathrm{I}_{\mathrm{F}}(\varphi)$, assim:

$$
\mathrm{I}=\mathrm{C}_{\mathrm{DL}} \frac{\mathrm{d} \varphi}{\mathrm{dt}}+\mathrm{I}_{\mathrm{F}}(\varphi)
$$

Porém, da relação $U=\varphi+$ RI pode-se obter a corrente total do sistema, ou seja I, resultando na igualdade:

$$
\mathrm{C}_{\mathrm{DL}} \frac{\mathrm{d} \varphi}{\mathrm{dt}}+\mathrm{I}_{\mathrm{F}}(\varphi)=\frac{\mathrm{U}-\varphi}{\mathrm{R}_{\text {total }}}
$$

A equação (2) relaciona os parâmetros do sistema, e pode ser utilizada para analisar o comportamento do potencial, por exemplo, em um regime de corrente total constante. 
Supondo um sistema nessas condições, ou seja, uma corrente externa é imposta, pode-se analisar através da equação qual será a resposta do sistema quando, por algum motivo qualquer, $\varphi$ sofre uma pequena perturbação $(\delta \varphi)$.

Assim aplicando a perturbação à equação e considerando que a corrente faradaica pode ser expressa por uma série de Taylor, que por sua vez, para pequenas perturbações pode ser truncada após do termo linear, temos a seguinte equação:

$$
\mathrm{C}_{\mathrm{DL}} \frac{\mathrm{d} \delta \varphi}{\mathrm{dt}}=-\frac{\partial \mathrm{I}_{\mathrm{F}}(\varphi)}{\partial \varphi} \delta \varphi-\frac{\delta \varphi}{\mathrm{R}_{\text {total }}}
$$

O termo $\partial \mathrm{I}_{\mathrm{F}}(\varphi) / \partial \varphi$ é definido como $\mathrm{Z}_{\mathrm{F}}^{-1}$, onde $\mathrm{Z}_{\mathrm{F}}$ é definido com a impedância faradaica (a freqüência zero), logo a equação pode ser rearranjada tomando a forma:

$$
\mathrm{C}_{\mathrm{DL}} \frac{\mathrm{d} \delta \varphi}{\mathrm{dt}}=-\left(\mathrm{Z}_{\mathrm{F}}^{-1}+\mathrm{R}_{\text {total }}^{-1}\right) \delta \varphi
$$

A equação (4) é muito interessante, pois pode-se ver claramente que se o termo $\left(\mathrm{Z}_{\mathrm{F}}^{-1}+\right.$ $\mathrm{R}_{\text {total }}{ }^{-1}$ ) for positivo, o efeito da perturbação diminuirá no tempo e esta situação corresponde ao comportamento de um sistema estável em que a resistência total é baixa, de forma que sua inversa seja grande, logo independentemente da impedância faradaica o segundo termo da equação é sempre negativo e portanto qualquer perturbação no potencial do sistema tende a desaparecer.

Para que o segundo termo da equação seja positivo o terno $\mathrm{Z}_{\mathrm{F}}^{-1}$ tem que ser negativo, ou seja, uma região de resistência diferencial negativa, como já citado acima, e $R_{\text {total }}$ tem que ser alto suficiente para que sua inversa, quando somada a $\mathrm{Z}_{\mathrm{F}}^{-1}$ não torne o termo positivo. Nessas condições uma perturbação tenderá a crescer com o tempo, e quando maior a variação da perturbação maior será o crescimento, causando assim uma espécie de explosão, onde o potencial mudará rapidamente de um valor para outro nessa região. 
A rápida variação de potencial pode, por exemplo, fazer com que o eletrodo fique rapidamente recoberto por uma camada de óxido, a formação dessas espécies faz com que intermediários da reação de fundo (em geral a oxidação de alguma espécie orgânica) que não foram completamente oxidados possam reagir, uma vez que sua oxidação completa necessita de espécies oxigenadas. A oxidação dessas espécies liberará elétrons e ocorrerá um aumento da corrente, como o sistema está em regime galvanostático (corrente constante) para se manter a mesma taxa de troca de elétrons o potencial diminui. O sistema pode novamente sofrer uma perturbação qualquer e o potencial aumentar dando origem a um novo ciclo.

Exemplos de oscilações sob diferentes condições de controle são encontrados em um dos osciladores eletroquímicos do tipo HN-NDR mais estudados: a reação de eletrooxidação de hidrogênio sobre platina na presença de $\mathrm{Cl}^{-}$e $\mathrm{Cu}^{2+}[11-15]$.

Para o caso específico da eletrooxidação de moléculas orgânicas pequenas como metanol e ácido fórmico, os intermediários $\mathrm{CO}_{\mathrm{ad}}$ e $\mathrm{O}(\mathrm{H})_{\mathrm{ad}}$ "bloqueiam" em diferentes potenciais a eletrooxidação direta e a cooperação entre os dois ciclos de retro-alimentação geralmente resulta na presença de oscilações de corrente e potencial sob algumas condições.

A Tabela 1 mostra, em linhas gerais, sistemas oscilatórios compostos de pequenas moléculas orgânicas em diferentes eletrólitos suportes e metais catalisadores. São mostrados oscilações tanto de potencial quanto de corrente e suas respectivas freqüências. 
Tabela 1 - Exemplos de sistemas oscilantes com pequenas moléculas orgânicas

\begin{tabular}{|c|c|c|c|c|c|}
\hline $\begin{array}{c}\text { Espécie } \\
\text { Eletroativa }\end{array}$ & $\begin{array}{c}\text { Metal } \\
\text { catalisador }\end{array}$ & $\begin{array}{c}\text { Eletrólito } \\
\text { suporte }\end{array}$ & $\begin{array}{l}\text { Variável } \\
\text { oscilante }\end{array}$ & $\begin{array}{c}\text { Freqüência } \\
\text { de oscilação } \\
\text { / Hz }\end{array}$ & Ref. \\
\hline \multirow{4}{*}{ Formaldeído } & $\mathrm{Pt} / \mathrm{Pt}$ & $\mathrm{H}_{2} \mathrm{SO}_{4}$ & $\mathrm{E}$ & $0,2-0,6$ & {$[16,17]$} \\
\hline & \multirow{2}{*}{$\mathrm{Pt}$} & $\mathrm{H}_{2} \mathrm{SO}_{4}$ & $\mathrm{E}$ & $1-3$ & [18-20] \\
\hline & & $\mathrm{NaOH}$ & $\mathrm{E}$ & - & [21] \\
\hline & $\mathrm{Rh}$ & $\mathrm{NaOH}$ & I & $1-6$ & [21] \\
\hline \multirow{5}{*}{ Ácido Fórmico } & $\mathrm{Pd}$ & $\mathrm{HClO}_{4}$ & $\mathrm{E}$ & $(0,8-16) \cdot 10^{-3}$ & [22] \\
\hline & $\mathrm{Pt}$ & $\mathrm{HClO}_{4}$ & I & 1,2 & {$[23]$} \\
\hline & $\operatorname{Pt}(100)$ & $\mathrm{HClO}_{4}$ & I & $0,05-0,2$ & {$[23,24]$} \\
\hline & $\operatorname{Pt}(110)$ & $\mathrm{H}_{2} \mathrm{SO}_{4}$ & I & $0,3-1$ & [24] \\
\hline & $\operatorname{Pt}(111)$ & $\mathrm{H}_{2} \mathrm{SO}_{4}$ & I & 0,05 & {$[24]$} \\
\hline \multirow{4}{*}{ Metanol } & $\mathrm{Pt} / \mathrm{C}$ & $\mathrm{H}_{2} \mathrm{SO}_{4}$ & I & $0,2-0,3$ & {$[25]$} \\
\hline & \multirow{2}{*}{$\mathrm{Pt}$} & $\mathrm{H}_{2} \mathrm{SO}_{4}$ & $\mathrm{E}$ & $0,5-2$ & [26] \\
\hline & & $\mathrm{HClO}_{4}$ & $\mathrm{E}$ & $0,1-1,5$ & {$[27]$} \\
\hline & $\mathrm{Ni}(\mathrm{OH})_{2}$ & $\mathrm{NaOH}$ & $\mathrm{E}$ & $0,08-0,18$ & [28] \\
\hline Etanol & $\mathrm{Pt}$ & $\mathrm{NaOH}$ & $\mathrm{E}$ & - & [29] \\
\hline \multirow{2}{*}{ Etileno Glicol } & $\mathrm{Pt} / \mathrm{Pt}$ & $\mathrm{H}_{2} \mathrm{SO}_{4}+\mathrm{Fe}^{3+}$ & $\mathrm{E}$ & 0,5 & {$[30]$} \\
\hline & $\mathrm{Rh}$ & $\mathrm{NaOH}$ & $\mathrm{E}$ & 1,6 & [21] \\
\hline
\end{tabular}

Na literatura são encontrados vários estudos de sistemas eletroquímicos oscilantes, porém poucos são os trabalhos que fazem uma análise mais crítica dos processos. A maioria trata o assunto de forma especulativa em alguns casos tratando como meras curiosidades. 
Tal visão das oscilações está começando a ser mudada com o desenvolvimento de métodos mais rápidos e sensíveis de análise que permitem que as espécies envolvidas no processo oscilatório sejam determinadas, porém somente foram estudadas moléculas simples como ácido fórmico [31]. O estudo de sistemas envolvendo moléculas com mecanismo de reação um pouco mais complexo que o ácido fórmico, como metanol, ainda são um desafio.

Para o caso do etileno glicol, não obstante a complexidade oriunda da presença da ligação C-C, a competição entre diferentes rotas reacionais parece assumir papel de potencial candidata a causador de instabilidades cinéticas na oxidação eletrocatalítica do etileno glicol. Antes da abordagem específica desse tema, apresenta-se na próxima seção uma breve descrição de algumas características da eletrooxidação de etileno glicol sob o ponto de vista da eletrocatálise fundamental.

\section{2 - ELETROOXIDAÇÃo DE ETILENO GLICOL}

Nesta seção faz-se uma breve descrição de características do etileno glicol e de alguns trabalhos que estudaram a sua eletrooxidação em diferentes meios e com diferentes catalisadores.

A eletrooxidação do etileno glicol $\left(\mathrm{MM}=62 \mathrm{~g} \mathrm{~mol}^{-1}\right)$ a $\mathrm{CO}_{2}$ libera dez elétrons, resultando em uma densidade de energia similar à do metanol $\left(\mathrm{MM}=32 \mathrm{gmol}^{-1}\right)$ o qual libera seis elétrons na oxidação completa a $\mathrm{CO}_{2}$. Além do aspecto energético, o EG tem baixa toxicidade, pode ser obtido através da biomassa e, devido a seu alto ponto de ebulição (198 $\left.{ }^{\circ} \mathrm{C}\right)$, é pouco volátil. Todas essas características fazem do EG uma alternativa ao metanol em dispositivos geradores de energia como células a combustível [32]. 
A oxidação eletrocatalítica de EG pode ocorrer tanto em meio ácido como em meio alcalino. Em meio ácido o metal mais utilizado como catalisador é a Pt, sendo que os melhores efeitos catalíticos até o momento foram obtidos com eletrodos binários de Pt e Ru [33]. Observa-se nesse caso, uma forte dependência da proporção dos metais (Pt e Ru) no efeito catalítico, como relatado por Lima et al.[33]. Adicionalmente, observou-se que para valores de até $40 \%$ em Ru (proporção atômica) há predominância de um efeito promotor da reação, enquanto que composições com conteúdo de Ru maior que $40 \%$ a reação é inibida até atingir uma atividade mínima para um conteúdo de 100\% de Ru [34].

A eletrocatálise em meio alcalino sobre superfície de Pt apresenta-se mais eficiente do que em meio ácido, uma vez que a disponibilidade de espécies oxigenadas como $\mathrm{OH}$ na interface é maior em meio alcalino, favorecendo a oxidação de intermediários carbonáceos. Utilizando eletrodos de platina lisa, Hauffe e Heitbaum [35] estudaram a eletrooxidação de EG em $1 \mathrm{M}$ de $\mathrm{KOH}$ e observaram que a oxidação do álcool libera em media oito elétrons por molécula o que levou os autores a concluir que o oxalato era o produto majoritário. Os autores propuseram que a reação ocorre via desidrogenação de intermediários adsorvidos. Utilizando técnicas espectroscópicas Christensen e Hamnett [36] compararam a oxidação do etileno glicol catalisada por Pt em meios ácido $\left(\mathrm{H}_{2} \mathrm{SO}_{4}\right)$ e alcalino $(\mathrm{NaOH})$ e observaram que os principais produtos de oxidação em meio ácido são o ácido glicólico e o $\mathrm{CO}_{2}$, enquanto glicolato, oxalato e carbonato predominam em meio alcalino. Com base na referência [35] pode-se ilustrar de forma esquemática as possíveis vias para a eletrooxidação do EG em meio básico como mostrado na Figura 3. 


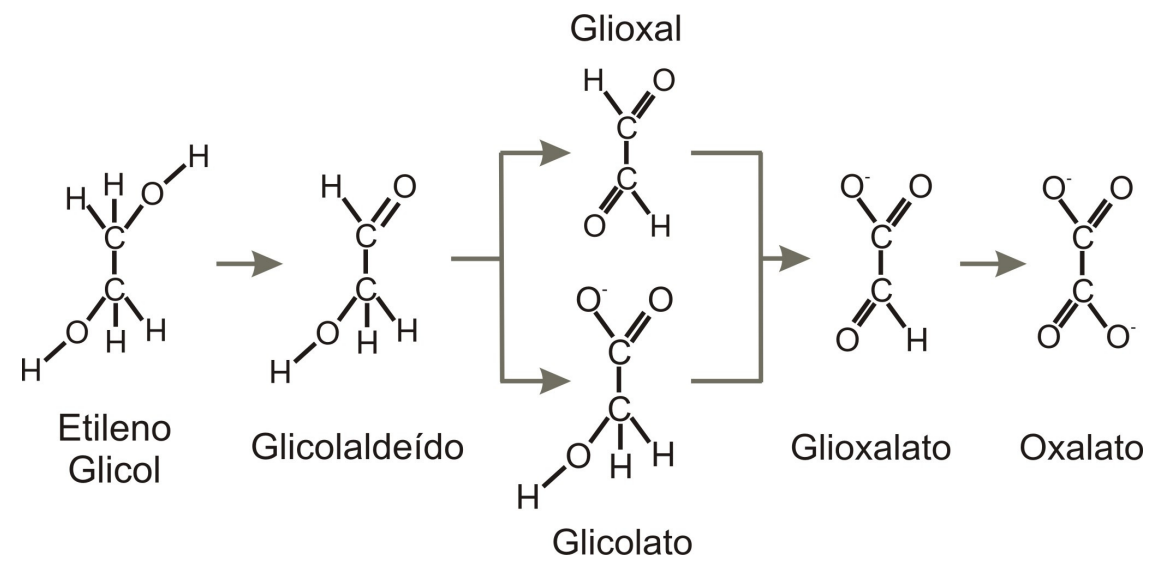

Figura 3 - Produtos de oxidação parcial do etileno glicol em meio alcalino.

Desconsiderando as complicações sobre a natureza específica das espécies adsorvidas propriamente ditas, são mostrados nesse esquema os intermediários e subprodutos eventualmente dessorvidos durante o processo. Grosso modo, quando não ocorre a quebra da ligação C-C, o produto mais oxidado que se pode obter é o oxalato (perda de oito elétrons do álcool), porém quando a ligação é rompida pode-se formar $\mathrm{CO}_{2}$, que por sua vez reage com $\mathrm{OH}^{-}$presente no meio formando $\mathrm{CO}_{2}{ }^{3-}$, além dos demais intermediários de oxidação contendo apenas um carbono (formiato e formaldeído).

Com base nessa breve descrição é possível afirmar que a que a eletrooxidação de EG possui um mecanismo complexo podendo seguir várias vias reacionais e produzir uma grande variedade de subprodutos. A presença das duas hidroxilas faz com que haja uma diminuição da força da ligação entre os dois carbonos facilitando assim a quebra dessa ligação e conseqüentemente gerando novas vias e subprodutos.

Aparentemente são apenas dois os resultados na literatura que apontam para a presença de instabilidades cinéticas na eletrooxidação de EG [21,30]. Corroborando a especulação apresentada aqui sobre a natureza mecanística das instabilidades, são relatadas nesses trabalhos oscilações de potencial sobre superfícies de platina em meio ácido [30] e de corrente sobre ródio em meio alcalino [21]. 
Os resultados com platina [30] são feitos com várias concentrações de EG na faixa de 0,2-1,6 M em regime galvanostático. Foram utilizados eletrodepósitos de platina com área geométrica de $10 \mathrm{~cm}^{2}$. Os resultados mostram oscilações caóticas a baixas concentrações de álcool e quase periódicas à medida que se aumenta a concentração. A corrente utilizada no experimento é de difícil interpretação uma vez que a mesma não é mantida constante, isto é, os resultados não são expressos na forma de densidade de corrente (o que seria o mais usual para medidas com eletrodepósitos) e o seu valor variou de 11 a $17 \mathrm{~mA}$, sendo que o texto não deixa claro que essa diferença é para compensar algum desvio da área do eletrodo ou por algum outro motivo. Porém observa-se que as medidas em regime galvanostático são apenas de caráter complementar nesse artigo, o principal tema abordado pelos autores são as oscilações em regime de potencial de circuito aberto em soluções contendo várias espécies orgânicas (porém é dada uma grande atenção ao EG) e sais de metais de alto número de oxidação como $\mathrm{Ce}^{4+} \mathrm{e} \mathrm{Fe}^{3+}$.

Os trabalhos com $\mathrm{Rh}$ [21] são mais rigorosos em relação às condições experimentais porém a grande quantidade de compostos orgânicos e os vários métodos empregados deixaram o trabalho com um caráter muito geral sobre o assunto. No que diz respeito às oscilações com EG, observou-se que ao longo de uma varredura linear de potencial $\left(0,05 \mathrm{mV} \cdot \mathrm{s}^{-1}\right)$ iniciada a $-0,9 \mathrm{~V}$ é interrompida a $0 \mathrm{~V}$ (ambos vs SCE) e nesse ponto a corrente passa a ser registrada em função do tempo. A solução utilizada foi de $0,1 \mathrm{M}$ de $\mathrm{NaOH}$ e EG + $6 \mu \mathrm{M}$ de $\mathrm{Rh}\left(\mathrm{NO}_{3}\right)$ a $34{ }^{0} \mathrm{C}$ sobre um fio de $\mathrm{Rh}$. Os autores somente dizem que as oscilações parecem ser bem regulares e sustentáveis por alguns minutos.

Sendo assim, qualquer inferência mais precisa sobre a dinâmica oscilatória presente na eletrooxidação do etileno glicol seria injustificável, tendo em vista o caráter geral dos experimentos disponíveis na literatura. Dignas de nota são ainda as observações relatadas na literatura sobre a presença de dinâmica oscilatória em reações envolvendo alguns 
intermediários e/ou subprodutos da eletro-oxidação de EG ilustrados na Figura 3, como o glioxal [21,30] e o glicoaldeído [21]. Tais observações só reforçam a idéia da existência de um acoplamento entre instabilidades cinéticas presentes na eletrooxidação do EG. Finalmente, acredita-se que a elucidação do mecanismo associado à ocorrência de tais instabilidades contribua como ferramenta adicional ao entendimento do processo eletrocatalítico em si. 


\section{2- OBJETIVOS}

O presente trabalho tem como objetivo o estudo das instabilidades dinâmicas da reação de eletrooxidação de etileno glicol catalisada por platina em meio alcalino. Parâmetros como a concentração de etileno glicol; a concentração do eletrólito suporte; a adição de intermediários de reação e a densidade de corrente aplicada em modo galvanostático foram estudados com o intuito de se entender melhor as variáveis que influenciam no processo oscilatório. 


\section{3 - MATERIAIS E MÉTODOS}

\section{1 - ELETRODOS}

Como eletrodo de trabalho utilizou-se uma placa de $\mathrm{Pt}$ com $0,52 \mathrm{~cm}^{2}$ de área geométrica e 2,8 de rugosidade (i.e., a razão entre áreas real e geométrica) e como contra eletrodo uma tela de Pt com alta área superficial.

Todos os potenciais foram medidos em relação a um eletrodo de referência de hidrogênio $(E R H)$ preparado com solução de composição idêntica à utilizada no eletrólito de suporte. Tal eletrodo de referência foi escolhido pela simplicidade em sua preparação e a possibilidade de limpeza do mesmo juntamente com os outros eletrodos sem problemas de contaminação além, da alta estabilidade ao longo do tempo, fator esse considerado primordial [37].

A escala de referência de potencial é baseada no equilíbrio da reação de oxidação de hidrogênio sobre platina platinizada em solução com atividade unitária de prótons e pressão de $\mathrm{H}_{2}$ igual a uma atmosfera [38]. A reação que determina o equilíbrio tem a seguinte forma:

$$
\mathrm{H}_{2} \rightleftharpoons 2 \mathrm{H}^{+}(\text {aq. })+2 \mathrm{e}^{-}
$$

Sendo que o potencial da mesma é dado por:

$$
\mathrm{E}^{\mathrm{HE}}=\mathrm{E}^{0, \mathrm{SHE}}+\frac{\mathrm{RT}}{\mathrm{F}} \ln \left(\frac{\mathrm{a}_{\mathrm{H}^{+}}}{\sqrt{\mathrm{P}_{\mathrm{H}_{2}}}}\right)
$$


Ou seja, quando a atividade protônica e a pressão de $\mathrm{H}_{2}$ são unitárias o potencial do eletrodo é igual ao potencial padrão da equação, que por definição é igual a zero.

Nas condições em que o eletrodo de referência foi utilizado (1 $\mathrm{M}$ de $\mathrm{KOH}$ ) seu valor está deslocado em relação em relação a escala padrão, tal deslocamento pode ser estimado utilizando a diferença de $\mathrm{pH}$ meio. Assim, trocando a base do logaritmo para 10 e considerando $\mathrm{P}_{\mathrm{H} 2}$ unitária tem-se

$$
\mathrm{E}^{\mathrm{HE}}=\mathrm{E}^{0, \mathrm{SHE}}+2,303 \frac{\mathrm{RT}}{\mathrm{F}} \log \left(\mathrm{a}_{\mathrm{H}^{+}}\right)
$$

O termo $\log \left(\mathrm{a}_{\mathrm{H}+}\right)$ é correspondente a $-\mathrm{pH}$. Considerando que as medidas foram realizadas a $25{ }^{0} \mathrm{C}$ tem-se um deslocamento da $\mathrm{a}_{\mathrm{H}^{+}}$de $-0,059 \mathrm{~V}$ no eletrodo para casa aumento

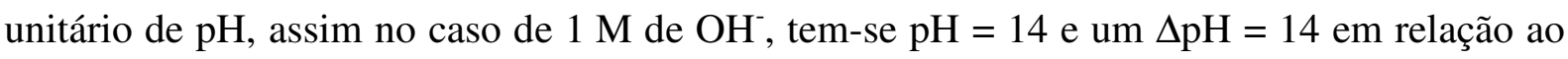
padrão, logo um deslocamento de $-0,826 \mathrm{~V}$. Como os eletrodos de referência são feitos com a mesma solução do eletrólito suporte a formação de $\mathrm{H}_{2}$ sobre platina ocorre sempre em $0 \mathrm{~V}$ versus o eletrodo de referência utilizado.

\section{2 - REAGENTES}

Para a realização das medidas utilizou-se:

- Água ultra pura (18,2 M $2 . \mathrm{cm}^{-1}$ Millipore $\left.^{\circledR}\right)$;

- Etileno glicol (98\% Mallinckrodt $\left.{ }^{\circledR}\right)$;

- Hidróxido de potássio (88\% J. T. Baker $\left.{ }^{\circledR}\right)$;

- Glicoladéido (98\% Fluka $\left.{ }^{\circledR}\right)$; 
- Ácido glicólico (98\% Alfa Aesar $\left.{ }^{\circledR}\right)$;

- Nitrogênio $\left(99,996 \%\right.$ White Martins $\left.^{\circledR}\right)$.

\section{3 - INSTRUMENTAÇÃO}

Todos os experimentos foram realizados em um potenciostato Autolab $^{\circledR}$ PGSTAT30002. Para a aplicação da resistência externa utilizou-se um sistema de ajuste variável de resistência da Minipa ${ }^{\circledR}$ modelo MDR610.

Para a pesagem dos reagentes sólidos utilizou uma balança analítica Sartorius ${ }^{\circledR}$ BP210S (precisão de $0,1 \mathrm{mg}$ ) e para as medidas de volumes uma micropipeta Boeco ${ }^{\circledR} 100$ $1000 \mu \mathrm{L}$.

\section{4 - Procedimentos Pré-EXPERIMENTAis}

Todos os componentes que entram em contato com o ambiente interno da célula eletroquímica são limpos por no mínimo 12 horas em solução alcalina de permanganato de potássio para oxidar espécies orgânicas eventualmente presentes. Após esse processo os componentes são imersos em solução de peróxido de hidrogênio para solubilização do permanganato adsorvido e aquecidos em água até a ebulição por no mínimo 3 vezes.

Antes e durante os experimentos as soluções foram deaeradas com $\mathrm{N}_{2}$. Antes de cada experimento o eletrodo é submetido a uma voltametria cíclica entre 0,05 e 1,5 V em solução de $\mathrm{KOH}$ por aproximadamente 50 vezes para se obter um perfil voltamétrico estável. Com base o voltamograma estável da platina calculou-se a área eletroquimicamente ativa do eletrodo através da integração da região de dessorção de hidrogênio. Considerou-se que a oxidação de uma monocamanda de hidrogênio nessa região produz $210 \mu \mathrm{C} . \mathrm{cm}^{-2}$ [39]. Todas 
as correntes foram normalizadas pela área eletroquimicamente ativa e então referidas como densidades de corrente.

Para não haver confusão dos potencias quando há aplicação de resistência externa em série entre o eletrodo de trabalho e o potenciostato, os potenciais com a aplicação da resistência externa serão denotados como $\mathrm{U}$ e os potenciais medidos apenas com a resistência da solução serão denotados como E, sendo assim enquanto U representa a soma de $\varphi+\mathrm{IR}_{\mathrm{ext}}+$ $\mathrm{IR}_{\text {sol }}, \mathrm{E}$ representa o caso particular onde $\mathrm{R}_{\mathrm{ext}}$ é zero, ou seja, $\mathrm{E}=\varphi+\mathrm{IR}_{\mathrm{sol}}$. 


\section{4 - Resultados e Discussão}

Neste capítulo são apresentados os resultados da eletrooxidação em regime não linear de etileno glicol sobre platina em meio alcalino. Inicialmente caracterizou-se as regiões de resistência diferencial negativa utilizando a técnica de espectroscopia de impedância eletroquímica. Estudou-se a eletrooxidação tanto em modo potenciostático quanto galvanostático, dando mais ênfase a esse segundo modo.

A influência de parâmetros como a densidade de corrente e a presença de intermediários foi estudada para melhor compreender os processos que regem as oscilações no sistema. Por fim é feita uma discussão geral dos resultados obtidos na seção.

\section{1 - ESPECTROSCOPIA DE IMPEDÂNCIA ELETROQUÍMICA}

As medidas de espectroscopia de impedância eletroquímica auxiliam no mapeamento das regiões de resistência diferencial negativa, que no caso de eletrooxidação de álcoois estão escondidas em medidas de voltametria cíclica. A Figura 4 mostra um voltamograma cíclico obtido em $1 \mathrm{M}$ de $\mathrm{KOH}$ e $0,4 \mathrm{M}$ de EG. Adicionalmente, a figura também mostra os diagramas de impedância obtidos em regime potenciostático em diferentes potenciais. Antes da medida de impedância o potencial do eletrodo foi variado a uma taxa constante (voltametria cíclica) de 0,05 à $1,4 \mathrm{~V}$ por 5 ciclos, o potencial então é fixado em $0,05 \mathrm{~V}$ e a partir desse ponto é realizado um salto potenciostático para o potencial de medida (indicado 
no gráfico). Os dados de impedância foram coletados $60 \mathrm{~s}$ após o salto para que a corrente torne-se mais estável. O potencial é perturbado a uma freqüência de $1 \mathrm{kHz}$ até $0,5 \mathrm{~Hz}$.

A voltametria foi realizada a $10 \mathrm{mV} . \mathrm{s}^{-1}$ para se obter uma boa aproximação da resposta equivalente ao estado estacionário. Os espectros obtidos a 0,8 e 0,9 V ilustram claramente a presença de uma resistência diferencial negativa, sendo que apenas a $0,9 \mathrm{~V}$ essa resposta encontra seu equivalente na voltametria. Dados os baixos valores de resistência ilustrados nos espectros obtidos a 0,8 e $0,9 \mathrm{~V}$, acredita-se que a região em que a H-NDR está contida esteja localizada entre esses dois potenciais (como verificado nos experimentos discutidos a seguir).

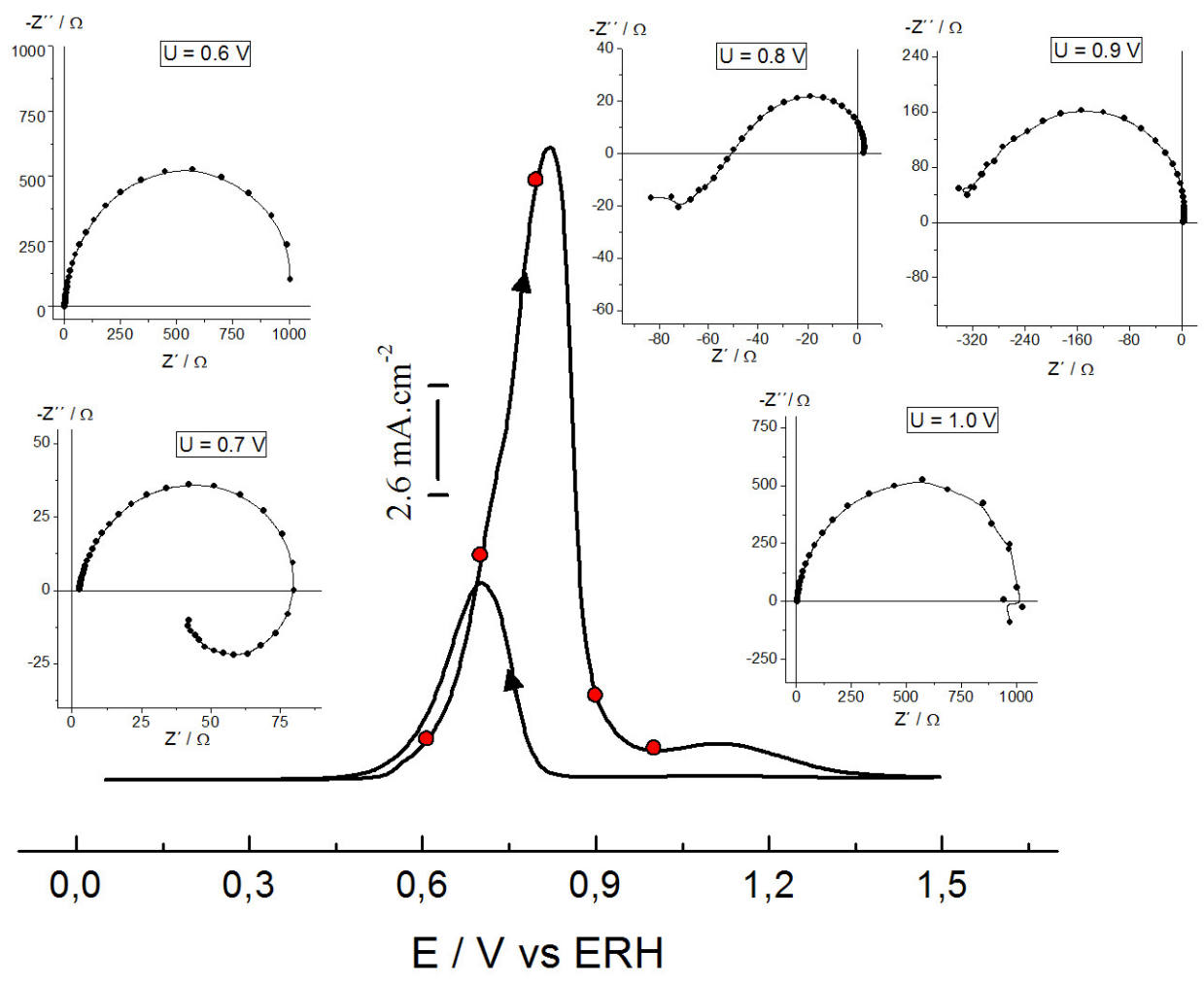

Figura 4 - Voltamograma cíclico (ao centro) obtido durante a eletrooxidação de EG $(0,4 \mathrm{M})$ em $\mathrm{KOH}(1 \mathrm{M})$ sobre platina. $\mathrm{v}=10 \mathrm{mV} \cdot \mathrm{s}^{-1}$. Nas bordas, são mostrados os diagramas de impedância. 


\section{2 - OSCilaÇões EM Modo Potenciostático}

Experimentos iniciais foram feitos em regime potenciostático com uma concentração 0,1 M de $\mathrm{KOH}$ e 0,4 M de EG. Ao contrário do que se usava corriqueiramente no laboratório, estas medidas não foram realizadas em modo potenciodinâmico a uma baixa velocidade de varredura (5-10 $\left.\mathrm{mVs}^{-1}\right)$ e sim em condições estritamente potenciostáticas, ou seja, o potencial inicialmente em $0.05 \mathrm{~V}$ foi subitamente elevado ao potencial de interesse e a série temporal de corrente coletada. Em regime potenciostático há necessidade de uma alta resistência no sistema para o mesmo apresentar comportamento oscilatório. Como o eletrólito não apresenta tal resistência, utilizou-se uma resistência externa. A magnitude dessa resistência externa $\left(\mathrm{R}_{\text {ext }}\right)$ é de 10 a 100 vezes maior que a apresentada pela solução, assim os resultados são discutidos considerando a resistência total como sendo a resistência aplicada e não a soma das duas $\left(\mathrm{R}_{\mathrm{ext}}+\mathrm{R}_{\mathrm{sol}}\right)$.

Foram analisados vários valores de potencial e resistência externa no período de 20 minutos, a ausência de oscilações nesse intervalo de tempo serviu de critério para classificar o sistema como estável. A Figura 5 mostra um exemplo de oscilações em modo potenciostático a $2 \mathrm{~V}$ (vs. ERH) e com $\mathrm{R}_{\mathrm{ext}}=200 \Omega$, as medidas passam por um período de indução de aproximadamente 5 minutos e, nesse caso, oscilam por cerca de 3 minutos. As oscilações iniciam-se de forma praticamente harmônicas (Figura 5a) e com o tempo aumentam a amplitude até o ponto que entram em uma janela caótica onde passam por estados de baixa amplitude e alguns picos agudos de alta amplitude como detalhado na Figura 5b. Após alguns ciclos caóticos o sistema passa a apresentar um comportamento mais simples (Figura 5c) em que oscilações de baixa amplitude se alternam com picos agudos, a frequiência dessas oscilações aumenta com o tempo até a diminuição brusca da corrente. A variação de potencial 
e da resistência externa não influencia a morfologia das oscilações, obviamente nos pares potencial e resistência em que o sistema apresenta oscilações.
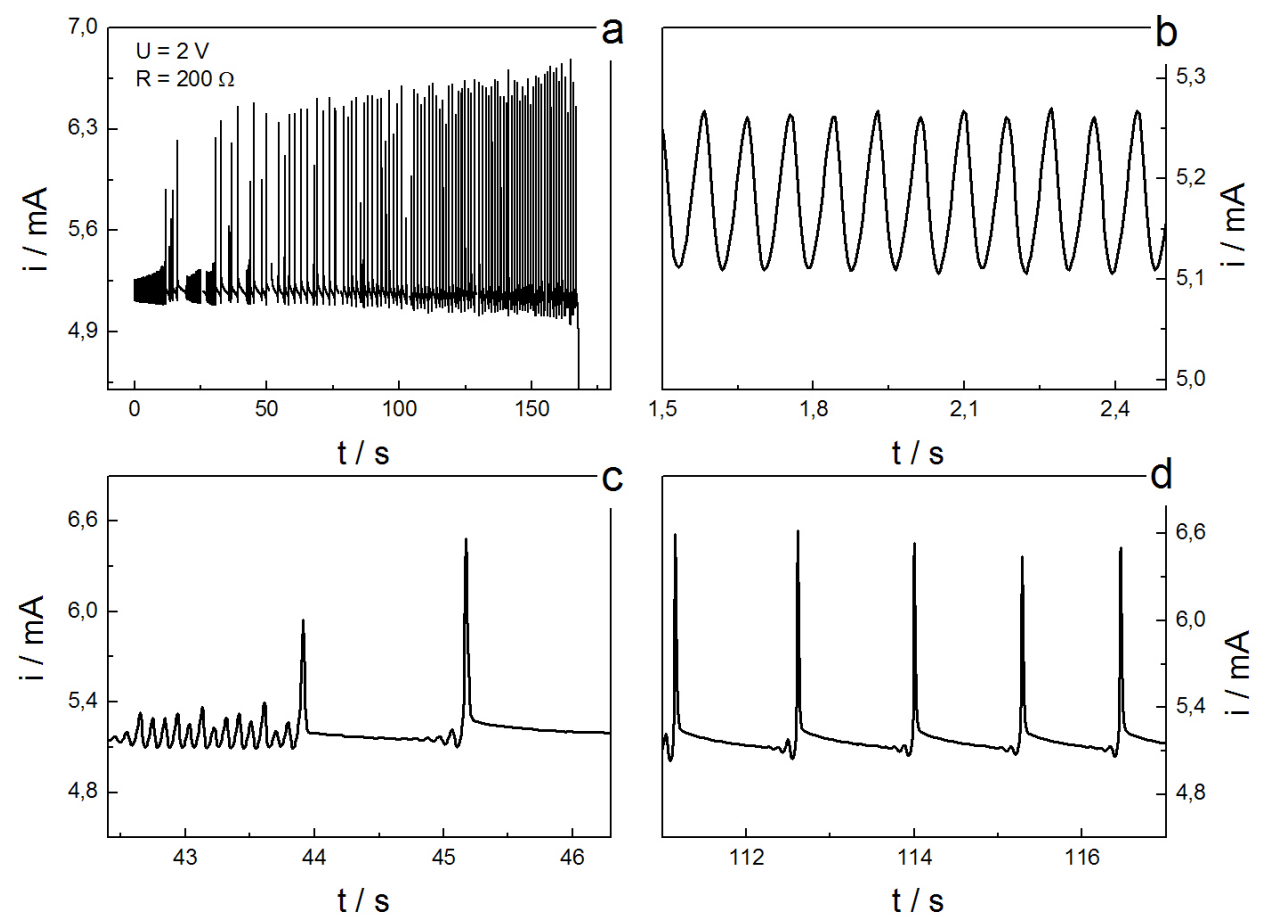

Figura 5 - Séries temporais obtidas sob controle potenciostático com $\mathrm{U}=2 \mathrm{~V}$ e $\mathrm{R}=200 \Omega$. Cronoamperometria em $0,1 \mathrm{M}$ de $\mathrm{KOH}$ e $0,4 \mathrm{M}$ de $\mathrm{EG}$, mostrando a região onde o sistema oscila (a) e os diferentes padrões encontrados (b-d).

Observam-se transições espontâneas na dinâmica com o passar do tempo, devido a algum parâmetro não controlável experimentalmente que varia em função do tempo. Tal parâmetro pode estar ligado, por exemplo, a um gradiente de concentração de alguma espécie, variações de temperatura, ou até mesmo a produção de intermediários que apresentam baixa difusão para a solução. Esta última hipótese é bem interessante e será discutida ao longo do trabalho. 
Após algumas medidas variando-se o potencial e a resistência externa é possível obter um diagrama em que se mostra de forma qualitativa a região onde o sistema apresenta instabilidades. A Figura 6 mostra o diagrama de bifurcação no plano $\mathrm{R}_{\mathrm{ext}} v s$. $\mathrm{U}$.

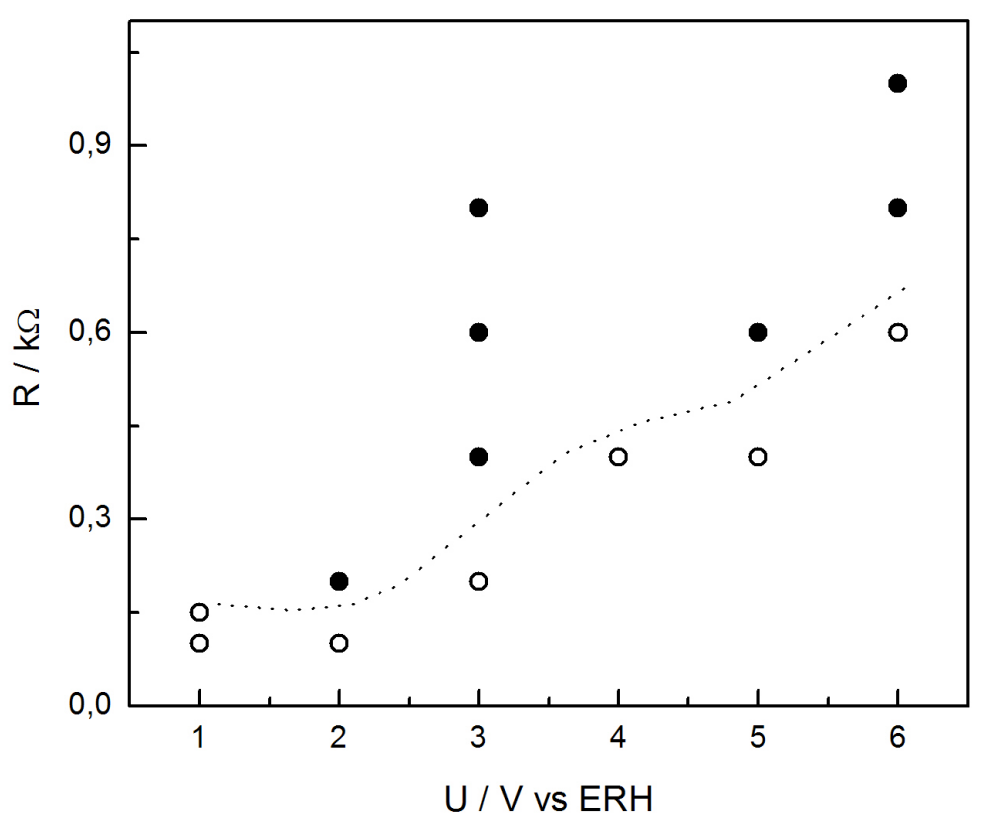

Figura 6 - Diagrama de bifurcação no plano $U$ vs $\mathrm{R}_{\text {ext }}$ mostrando parte da região onde o sistema apresenta comportamento oscilatório (círculos fechados) e onde o sistema não apresenta comportamento oscilatório (círculos abertos).

Os círculos abertos correspondem ao pares de pontos ( $\left.\mathrm{R}_{\mathrm{ext}} \mathrm{vs} \mathrm{U}\right)$ em que o sistema não apresenta oscilações. Os círculos fechados correspondem à região oscilatória. A baixos pares de potencial resistência o sistema não apresenta oscilações enquanto que com o aumento do potencial e da resistência o sistema passa a oscilar em uma região maior. Quando essa curva é extrapolada para valores muito altos de potencial e resistência tem-se um regime galvanostático. 


\section{3 - OSCILAÇÕES EM MODO GALVANOSTÁTICO}

Os experimentos em regimes galvanostáticos não necessitam de uma resistência externa para apresentarem oscilações uma vez que sob tal modo a própria resistência do circuito eletrônico do potenciostato faz com que as condições apresentadas na seção 1.1 para que ocorra instabilidades sejam satisfeitas [13].

A Figura 7 mostra exemplos dessas oscilações para uma densidade de corrente de 1,5 mA.cm ${ }^{-2}$, a morfologia das oscilações é bem similar em ambos os casos, permitindo dizer que ambos os sistemas iniciam com oscilações quase harmônicas, passam por uma janela caótica e logo após há alternância entre períodos de baixa amplitude e picos agudos.
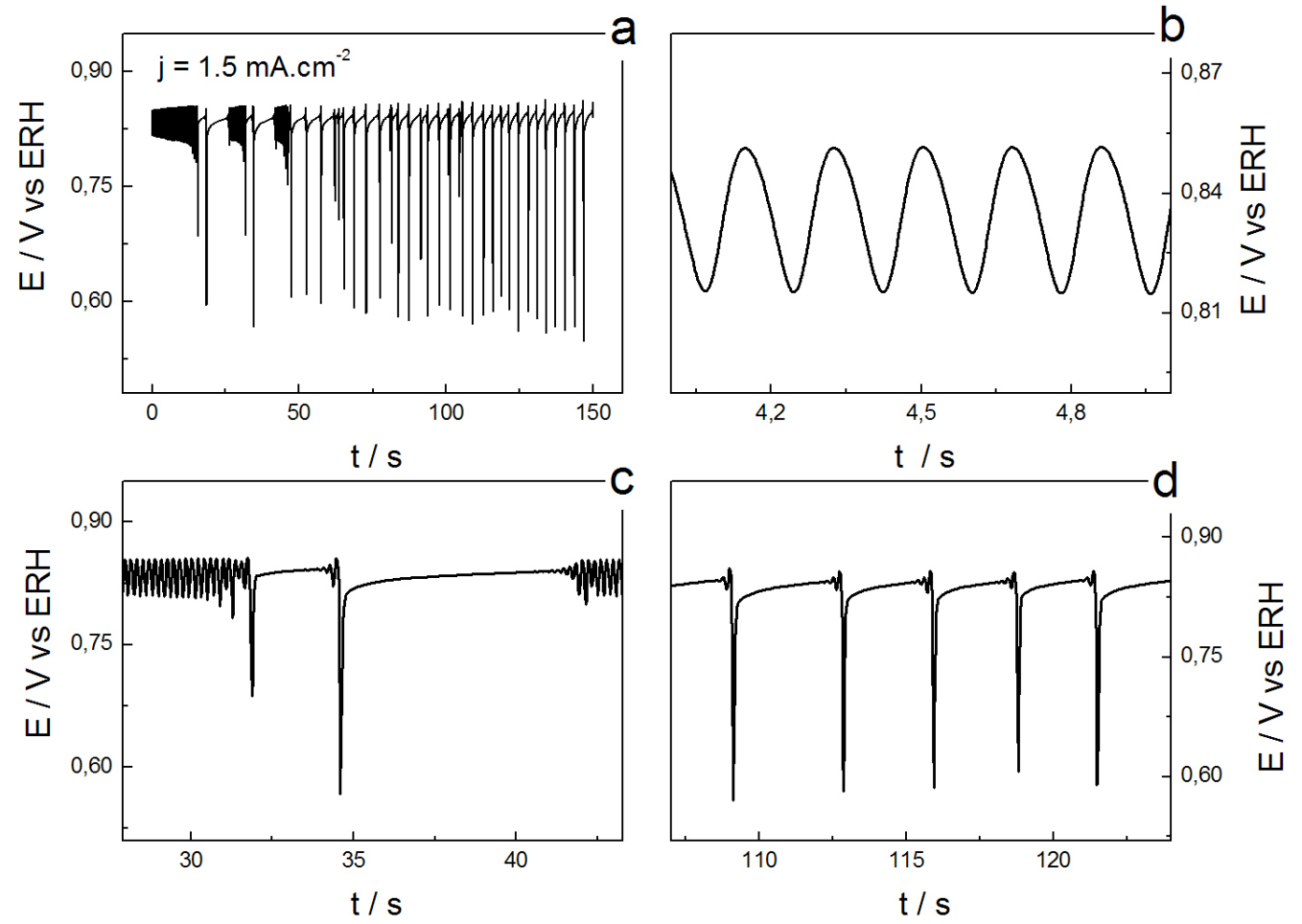

Figura 7 - Cronopotenciometria em solução 0,1 M de KOH 0,1 M e 0,4 M de EG mostrando a região onde o sistema oscila (a) e os diferentes padrões encontrados $(b-d)$. 
As oscilações quase harmônicas do sistema apresentam uma frequiência bem maior que as encontradas na literatura para moléculas orgânicas como: metanol [18,*], formaldeído [18,19] e ácido fórmico [*,40], ver Tabela 1. a título de comparação, a Figura 8 mostra oscilações de potencial (em regime galvanodinâmico) de metanol e ácido fórmico em ácido sulfúrico. Observa-se que as oscilações no caso do metanol variam de 0,33 a 0,67 Hz enquanto que as oscilações para ácido fórmico estão em torno de $0,3 \mathrm{~Hz}$. No caso do etileno glicol a freqüência das oscilações quase harmônicas (Figura 7b) são maiores que $6 \mathrm{~Hz}$.
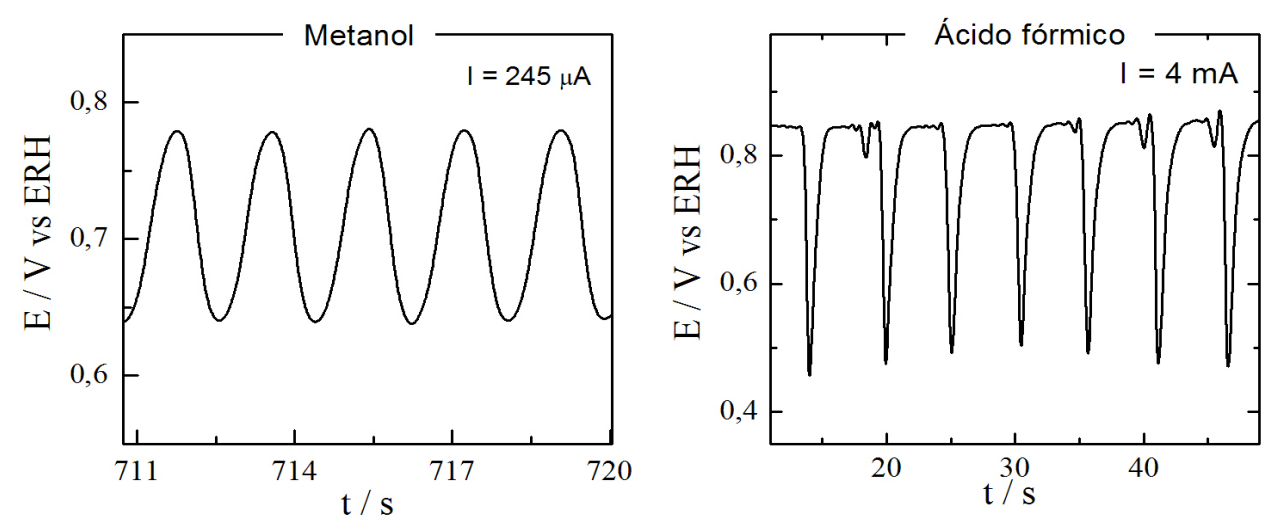

Figura 8 - Perfis de oscilação de potencial sob regime galvanodinâmico no sistema metanol $(0,68 \mathrm{M}), \mathrm{H}_{2} \mathrm{SO}_{4}(0,49 \mathrm{M})$ e ácido fórmico $0,1 \mathrm{M}, \mathrm{H}_{2} \mathrm{SO}_{4}$ $0,5 \mathrm{M}[*]$.

\subsection{1 - A INFLUÊNCIA DA CONCENTRAÇÃO}

Em medidas prévias observou-se que as oscilações são muito mais ricas morfologicamente quando a concentração de $\mathrm{KOH}$ é de $1 \mathrm{M}$, dessa forma esse valor foi mantido constante e a concentração de EG foi variada. A Figura 9 mostra varreduras lineares

* MARTINS, A. L.; BATISTA, B.; SITTA, E.; VARELA, H. Oscillatory instabilities during the electrocatalytic oxidation of methanol on platinum, Journal of the Brazilian Chemical Society, 2007 - submetido. 
de potencial $\left(0.05 \mathrm{~V} . \mathrm{s}^{-1}\right)$ em distintas concentrações de EG que variam de 0 (somente eletrólito suporte $1 \mathrm{M}$ de $\mathrm{KOH}$ ) a $1,6 \mathrm{M}$, observa-se que nessa faixa quanto maior a concentração maior a corrente máxima de oxidação e ocorre um deslocamento do potencial de pico para valores mais negativos. Para baixas concentrações observa-se um pré-pico provavelmente relacionado à oxidação de algum intermediário. Após o pico máximo a corrente se mantém ainda consideravelmente alta até cerca de $1,1 \mathrm{~V}$ e depois diminui.

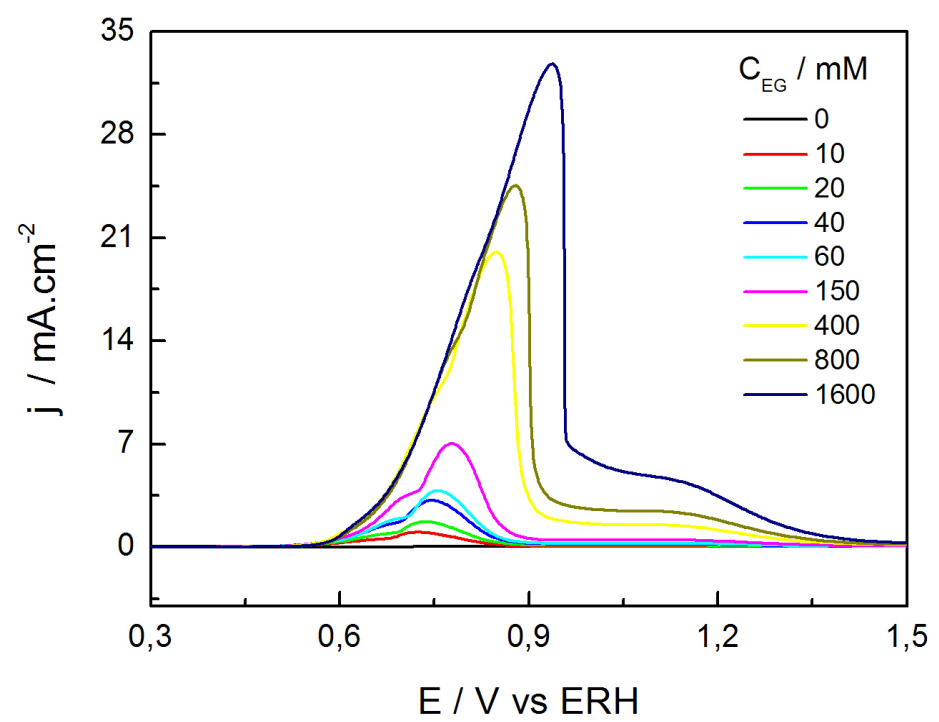

Figura 9 - Varredura linear a $0,05 \mathrm{~V} . \mathrm{s}^{-1}$ em $1 \mathrm{M}$ de $\mathrm{KOH}$ e diferentes concentrações de EG.

Para auxiliar a interpretação das oscilações traçaram-se mapas de Lorenz para as janelas de padrões observados. Os mapas de Lorenz consistem em graficar os valores mínimos (ou máximos) da variável que está oscilando em função dessa mesma variável transladada de uma fase, ou seja, no caso das oscilações em regime galvanostático grafica-se o valor do potencial do primeiro pico contra o potencial do segundo pico, do segundo contra o terceiro e assim sucessivamente, para oscilações de período 1, cujo valor de potencial é 
sempre o mesmo a resposta encontrada é apenas um ponto, para período dois, dois pontos e assim por diante. Quando se usa esse procedimento em uma janela caótica o resultado é uma figura pitoresca cuja forma se aproxima da letra " $v$ ". Na verdade o mapa de Lorentz nada mais é do que uma mudança de coordenadas. As considerações a seguir estão baseadas no trabalho Okamoto et al.[19]. Gerando mais uma coordenada através de uma relação entre as variáveis ou simplesmente atrasando uma das variáveis em $\tau$ segundos e com esses resultados constrói-se um atrator como o mostrado na Figura 10a, uma vez de posse desse atrator determina-se a chamada seção de Poincaré, que pode ser por exemplo $\mathrm{E}(\mathrm{t}+\tau)=\mathrm{E}(\mathrm{t}+2 \tau)$, essa relação representa um plano quando graficada nos mesmos eixos da Figura 10a, como mostrado na Figura 10b. Quando se confrontam os dois resultados, ou seja, os pontos em comum, se obtém figuras como a da Figura 10c para cada ciclo n e quando se plota $E(t+\tau)(n)$ contra $E(t+\tau)(n+1)$ obtém-se a Figura 10d que é uma representação similar ao mapa de Lorenz. Essas representações são ferramentas importantes, pois permitem condensar padrões temporais apresentando-os em gráficos mais simples. 

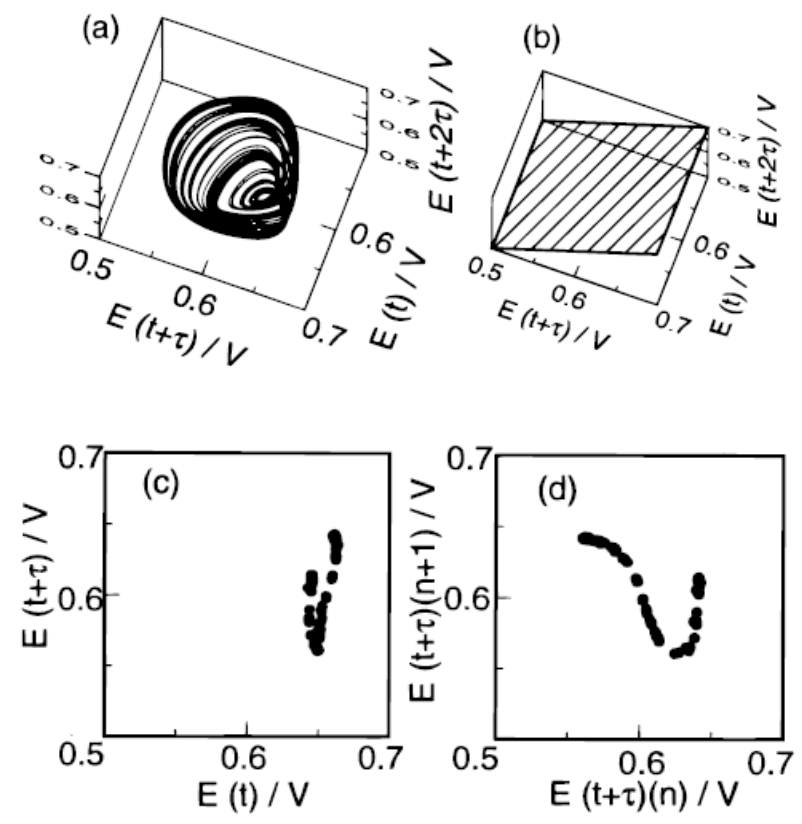

Figura 10 - (a) o atrator gerado pelo atraso $\tau$; (b) seção de Poincaré $E(t+\tau)=$ $\mathrm{E}(\mathrm{t}+2 \tau)$; (c) intersecção do atrator com a seção de Poincaré e (d) mapa unidimensional construído através da seção de Poincaré [19].

A Figura 11 apresenta os padrões encontrados com os respectivos mapas de Lorenz e traz a representação do formato da variação de potencial no tempo sem contar o período de indução, ou seja, a corrente é mantida fixa e após segundos antes do início das oscilações (o valor do potencial é um indicativo do início) e o potencial começa ser registrado. Optou-se em mostrar o formato de maneira esquemática (e não os resultados in natura) uma vez que o período das oscilações é muito pequeno, assim, na faixa de tempo de todo o período seria possível somente observar os limites inferiores e superiores, de forma que os limites de potencial foram desenhados e informações adicionais colocadas dentro dos mesmos.

No experimento da Figura 11 utilizou-se como eletrólito, $1 \mathrm{M}$ de $\mathrm{KOH}$ e 0,15 M de EG. Esse foi o menor valor de concentração utilizado por que se optou em trabalhar com a $3,4 \mathrm{~mA} \cdot \mathrm{cm}^{-2}(5 \mathrm{~mA})$ e em concentrações menores de álcool o sistema tem que desprender oxigênio para conseguir manter tal corrente. Nota-se que as oscilações já se iniciam com uma considerável amplitude e ao longo do tempo observa-se que o limite inferior aumenta muito 
mais que o superior até que em um ponto o potencial aumenta bruscamente para valores onde ocorre produção de oxigênio. Em destaque na figura é mostrado um diagrama de setor que relaciona a contribuição de cada morfologia no tempo total de oscilação. Para esta concentração de EG obteve-se de $52 \mathrm{~s}$ de oscilações.

Após o período de indução as oscilações iniciam-se de forma harmônica e após alguns segundos mudam a morfologia de forma bem sutil, em todo o período de oscilação somente observam-se oscilações de período 1. Uma análise mais quantitativa mostra que o sistema passou cerca de $25 \%$ do tempo de oscilação na primeira morfologia apresentada (preta) e os demais $75 \%$ na segunda (cinza). Os mapas de Lorenz mostram um conjunto de pontos de se estende pela reta bissetriz, isso significa que a amplitude das oscilações aumenta com o tempo, tal variação se torna mais sutil no segundo padrão de oscilações, fato comprovado pelo conjunto de pontos estarem mais junto. 

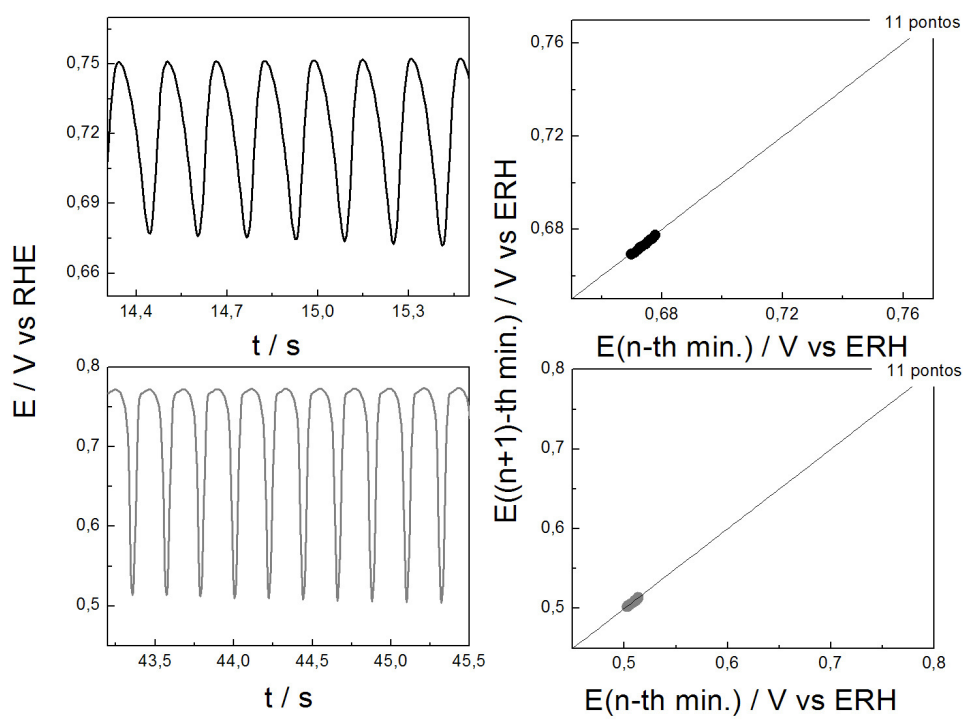

(a)

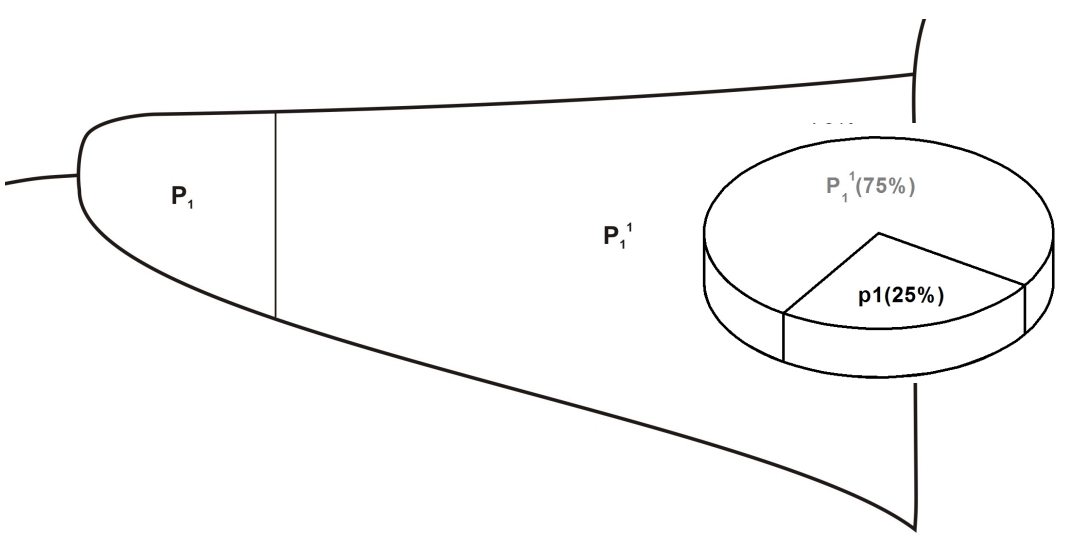

(b)

Figura 11- (a) padrões de oscilação encontrados em regime galvanostático (lado esquerdo) e correspondentes mapas de Lorenz (lado direito). (b) Perfil geral do potencial em função do tempo e proporção em que cada padrão operou. j = 3,4 mA.cm ${ }^{-2}$ Soluções: $1 \mathrm{M}$ de KOH e 0,15 M de EG.

No lado superior esquerdo dos mapas de Lorenz são mostrados a quantidade de pontos que foram utilizados para a construção da figura. Tal informação segue nas demais figuras análogas que aparecem ao longo do capítulo.

Quando a concentração de EG é aumentada para 0,4 M mantendo os demais parâmetros constantes nota-se uma grande diferença tanto no tempo em que o sistema passa 
oscilando (678 s) quanto no que se diz respeito à morfologia das oscilações. Como mostrado na Figura 12, a escala de tempo abaixo corresponde ao inicio das oscilações, descontando o período de indução. As oscilações iniciam-se praticamente harmônicas, como mostrado na Figura 12b, passando para uma janela caótica que é bem notada no mapa de Lorentz. Após esse período o sistema volta a apresentar um padrão bem definido onde se pode ver 3 pequenos ciclos acompanhados de um de amplitude bem maior. A presença de oscilações de período 4 não é vista no mapa de Lorenz uma vez que os dois primeiros ciclos são muito similares ficando ambos agrupados no conjunto localizado no canto superior esquerdo, a distinção dos dois conjuntos foi mostrada com o auxílio de círculos.

Após o aparecimento de período 4, o sistema volta a apresentar um comportamento caótico. Quando o sistema volta a apresentar um padrão, este passa por um padrão complexo com 3 ciclos de baixa amplitude acompanhados de um de alta amplitude. Três ciclos de baixa amplitude se repetem, porém o último ciclo é de maior amplitude quando comparado com o da primeira série e o pico de grande amplitude possui uma amplitude menor do que o seu "correspondente" na série anterior. Este padrão se repete (não é caótico) como mostrado no mapa de Lorenz que possui 6 grupos de pontos (novamente só vistos com o auxílio de círculos). $\mathrm{O}$ sistema ainda passa por padrões 3 e 2 que duram vários minutos até finalmente alcançar um período 1 e logo após o potencial aumenta bruscamente para regiões de desprendimento de oxigênio.

Esta medida quando comparada com a anterior mostra-se bem mais rica em relação a diversidade de padrões e no tempo que o sistema passa oscilando, uma fato interessante a ser notado é que ambas iniciam e terminam com o mesmo padrão. Outra comparação que pode ser feita é entre esta medida e a realizada com $0,1 \mathrm{M}$ de $\mathrm{KOH}$, tendo em vista que ambas contém a mesma concentração de EG: neste aspecto o único ponto em comum é o início quase harmônico das oscilações, ou seja, claramente não é apenas a concentração do álcool 
que determina a dinâmica. Tal fenômeno mostra que a oxidação do álcool envolve a participação de espécies oxigenadas do meio, de forma que, nesse caso específico, o aumento da concentração de $\mathrm{OH}^{-}$resulta em uma profunda modificação do padrão oscilatório. A participação de espécies oxigenadas é um assunto bem debatido em eletrocatálise, atualmente acredita-se que o mecanismo de oxidação de moléculas orgânicas sobre metais segue um mecanismo de Langmuir- Hinshelwood [41] em que o complexo ativado é formado por duas espécies adsorvidas. Como os padrões a $1 \mathrm{M}$ de $\mathrm{KOH}$ são bem mais diversificados optou-se em trabalhar com este como já mencionado anteriormente.

Nos períodos 6 e 4 a proximidade das intensidades das oscilações faz com que os conjuntos de pontos se fundam nos mapas de Lorenz. Para não haver confusão entre o número do período e o número de conjunto de pontos no mapa de Lorenz os conjuntos foram separados por círculos como mencionado anteriormente. 

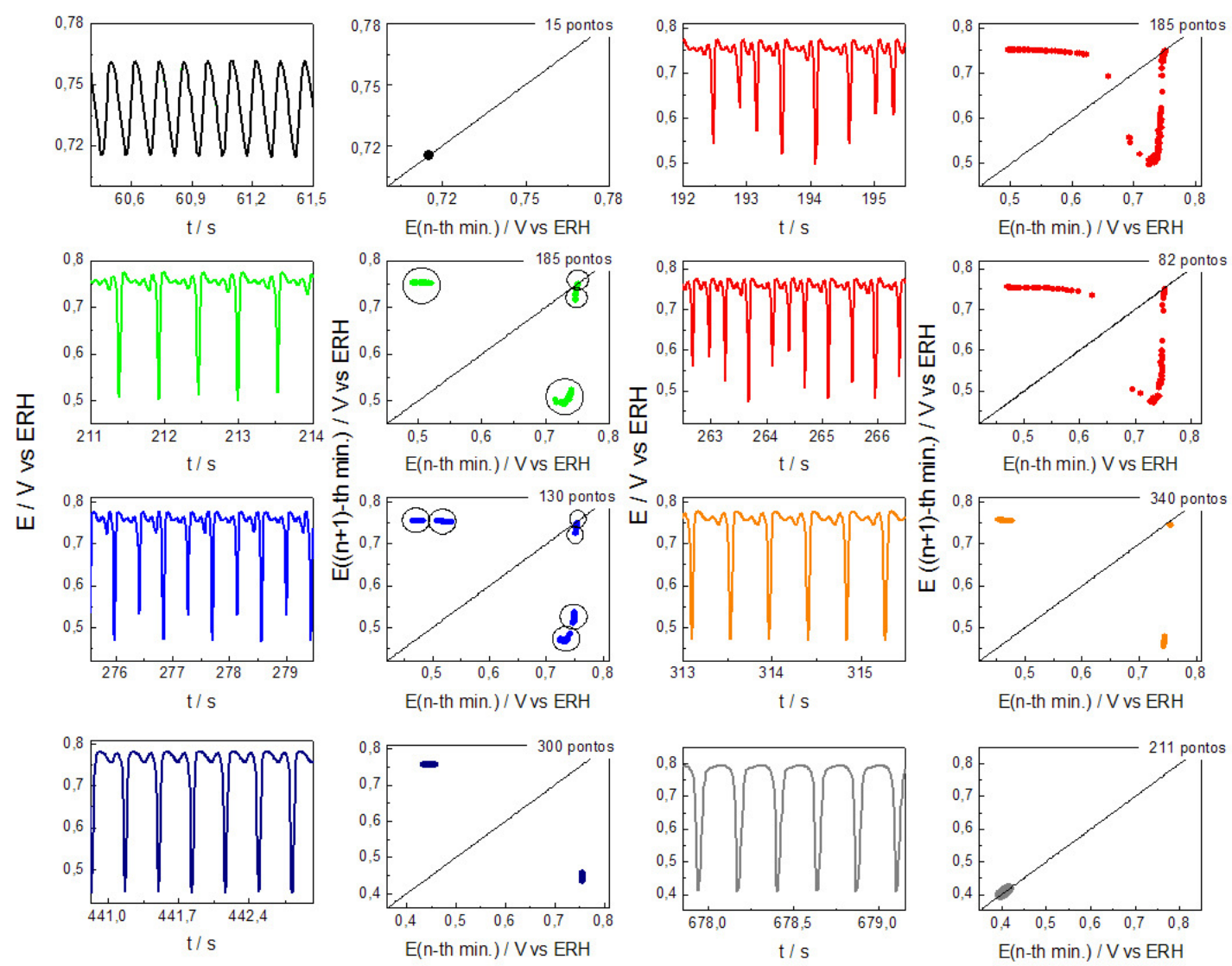

(a)

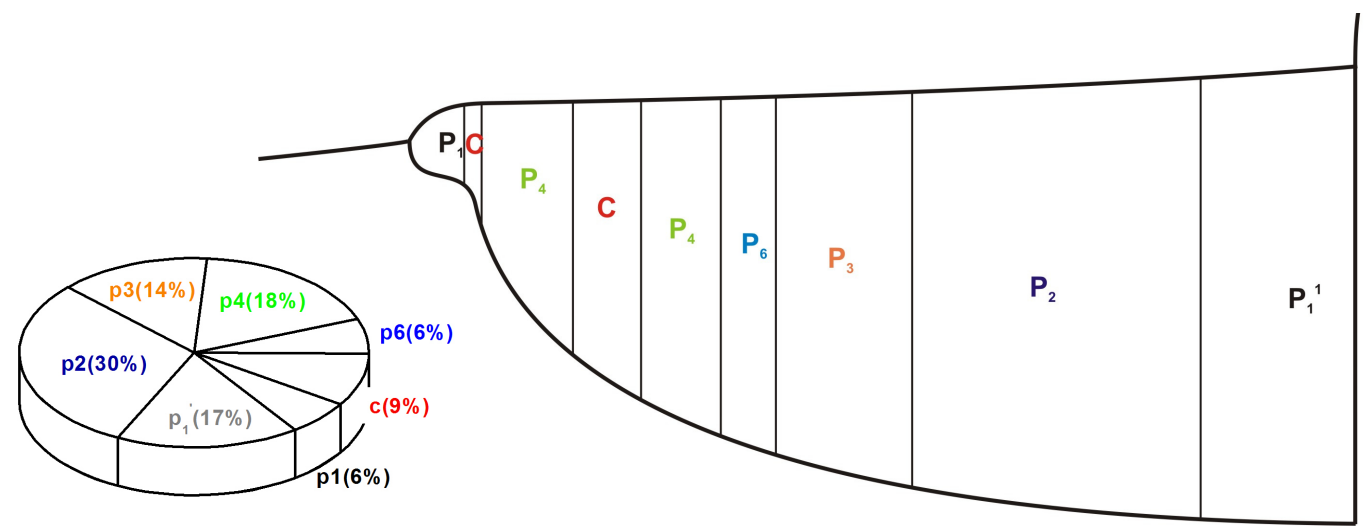

(b)

Figura 12 - (a) Padrões de oscilação encontrados em regime galvanostático e os correspondentes mapas de Lorenz (sempre a direita do gráfico correspondente) e (b) Perfil geral do potencial em função do tempo e proporção em que cada padrão operou. $\mathrm{j}=3,4 \mathrm{~mA} \cdot \mathrm{cm}^{-2}$ Soluções: $1 \mathrm{M}$ de $\mathrm{KOH}$ e 0,4 M de EG. 
No início da seção foi explicado como o mapa de Lorenz poderia ser construído a partir de um atrator, porém um atrator também pode ser construído a partir de um conjunto de pontos. O procedimento consiste na geração de uma nova variável partindo de um atraso $(\tau)$ no tempo de um conjunto de pontos já existente (no presente caso o potencial E). O resultado é um atrator em 2 dimensões quando $\mathrm{E}(\mathrm{t})$ é confrontado com $\mathrm{E}(\mathrm{t}-\tau)$. Se for construído mais um conjunto de pontos representando uma terceira variável utilizando $\mathrm{E}(\mathrm{t}-2 \tau)$ pode-se construir um atrator em 3 dimensões, porém a visualização no mesmo é difícil. Como exemplo desse procedimento foram construídos atratores em 2 dimensões para os padrões 2, 3 e caótico. A Figura 13 mostra os atratores.
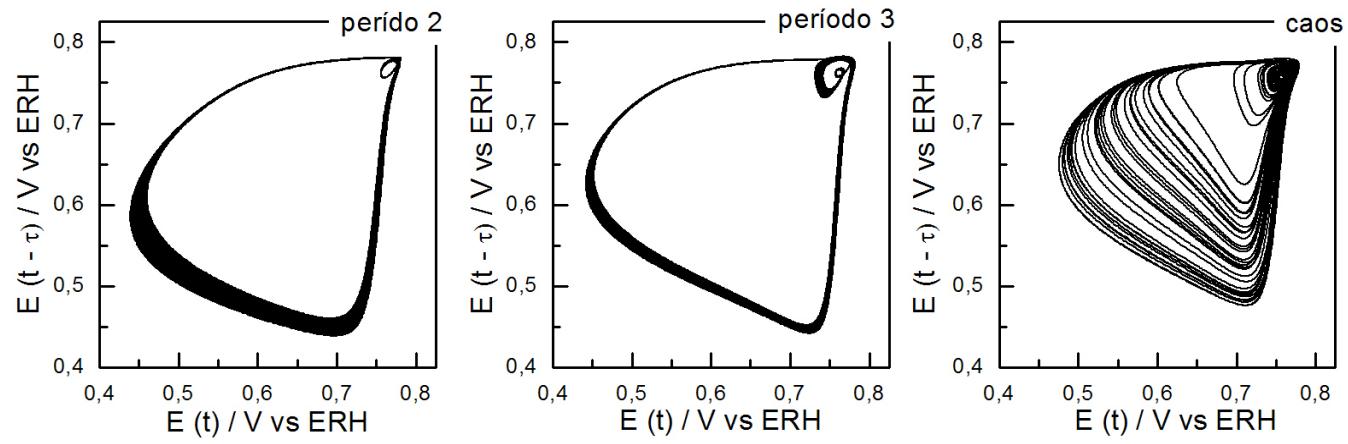

Figura 13 - Atratores em 2 dimensões gerados a partir dos padrões de períodos 2,3 e caótico.

Seguindo a mesma linha de raciocínio foi adicionada quantidade suficiente de EG para uma concentração final de 0,8 M e mantendo-se as mesmas condições das medidas anteriores. A Figura 14 mostra os resultados obtidos. 

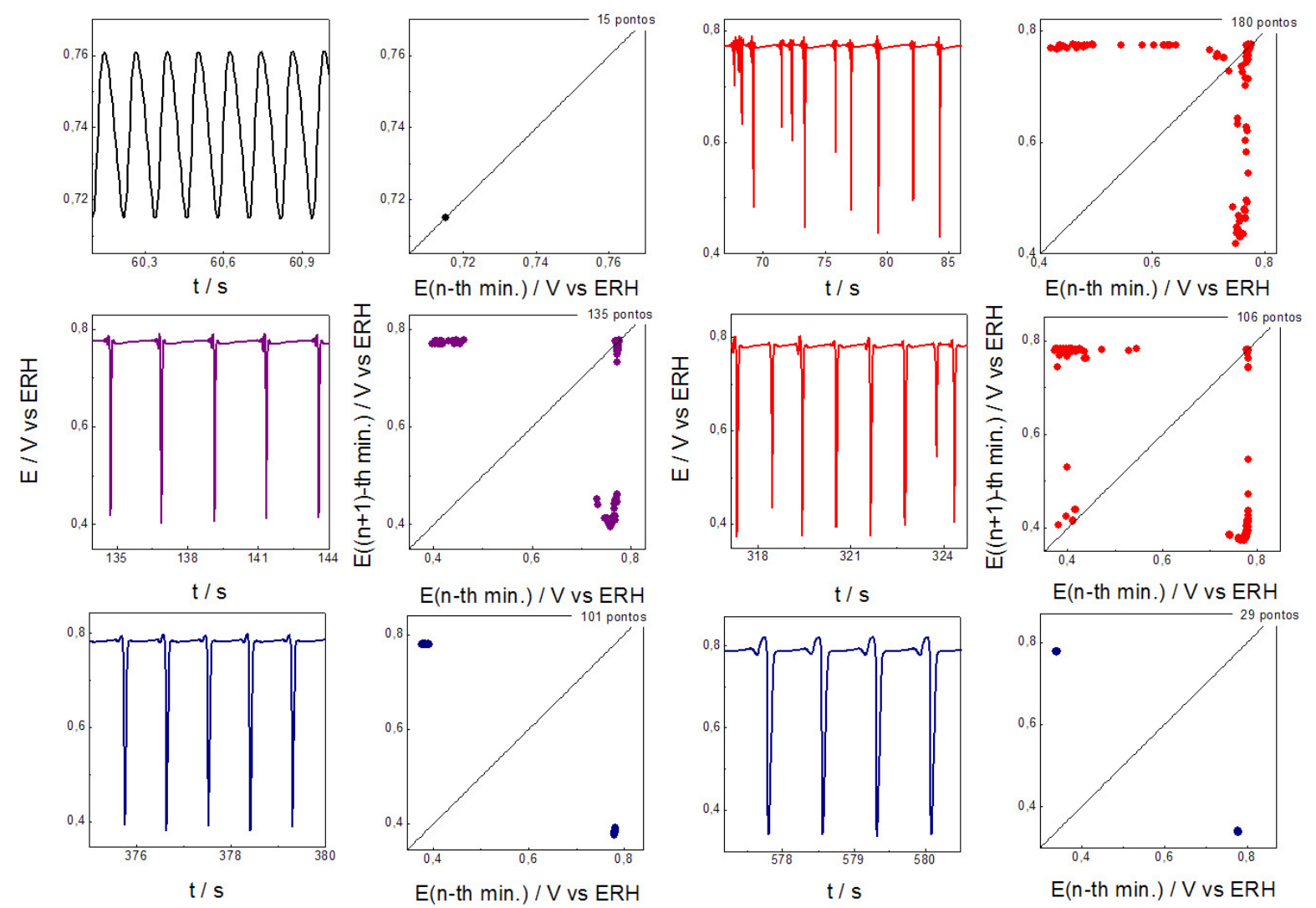

(a)

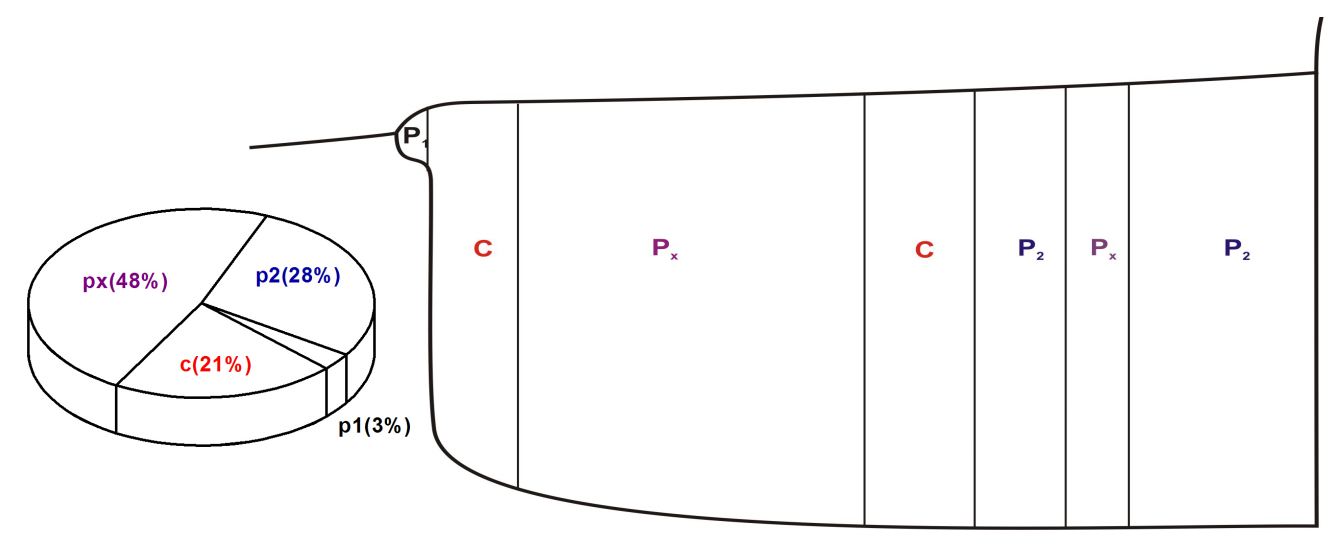

(b)

Figura 14 - (a) Padrões de oscilação encontrados em regime galvanostático e os correspondentes mapas de Lorenz e (b) Perfil geral do potencial em função do tempo e proporção em que cada padrão operou. $\mathrm{j}=3,4 \mathrm{~mA} \cdot \mathrm{cm}^{-2}$ Soluções: $1 \mathrm{M}$ de $\mathrm{KOH}$ e 0,8 M de EG.

Observa-se mais uma vez o início quase harmônico das oscilações passando por um uma janela caótica, porém quando o padrão é restaurado este apresenta-se de uma forma 
distinta do apresentado com $0,4 \mathrm{M}$, neste caso observa-se também um padrão de baixa amplitude acompanhado de um pico, com o passar do tempo o padrão de baixa amplitude tende a desaparecer dando lugar a um período 2. Ao contrário da grande mudança do tempo em que o sistema passa oscilando ocorrido quando se mudou a concentração de EG de $0,15 \mathrm{M}$ para $0,4 \mathrm{M}$, a mudança de 0,4 para $0,8 \mathrm{M}$ não teve grande variações (678 s como já mencionado para o primeiro contra $624 \mathrm{~s}$ para o segundo) A adição de EG para uma concentração de 1,6 M faz com que o sistema apresente maiores janelas caóticas e padrões menos definidos (Figura 15) e o tempo que o sistema passa oscilando é proporcional aos encontrados para 0,4 e $0,8 \mathrm{M}(632 \mathrm{~s})$.
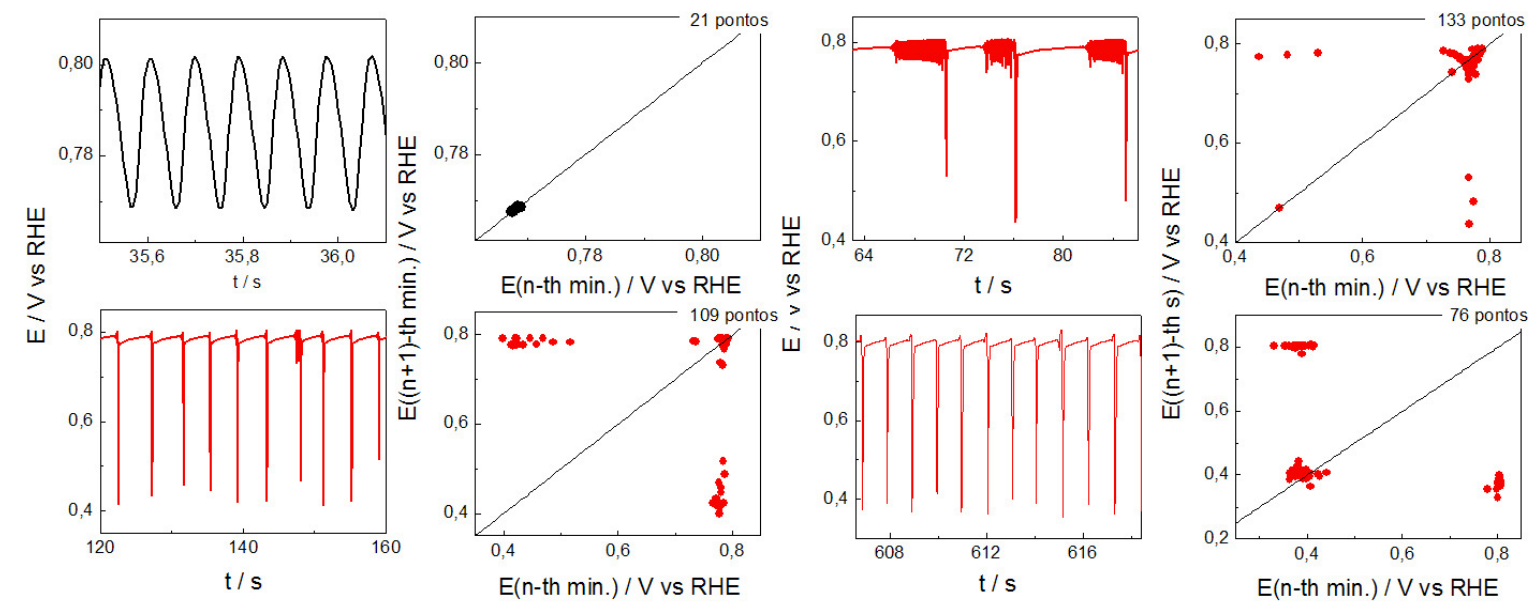

(a)

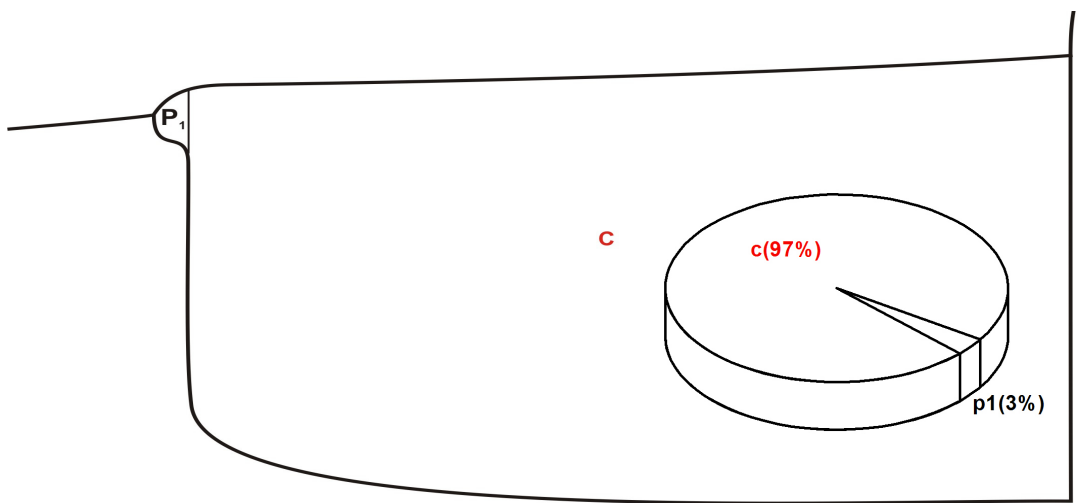

(b)

Figura 15 - (a) Padrões de oscilação encontrados em regime galvanostático e os correspondentes mapas de Lorenz e (b) Perfil geral do potencial em função do tempo e proporção em que cada padrão operou. $\mathrm{j}=3,4 \mathrm{~mA} \cdot \mathrm{cm}^{-2}$ Soluções: $1 \mathrm{M}$ de $\mathrm{KOH}$ e 1,6 M de EG. 
Foram mostradas 3 diferentes regiões durante o regime caótico, a primeira, logo após as oscilações quase harmônicas, onde se observam períodos de alta amplitude seguidos de regiões onde o potencial praticamente não oscila. Após esse período o sistema entra em um regime com oscilações de baixa amplitude seguido de picos agudos. Com o passar do tempo esses picos tornam-se mais freqüentes e estruturas irregulares dominam a dinâmica. Para exemplificar as mudanças que ocorrem nesta janela caótica ao longo do processo oscilatório são mostradas várias figuras em diferentes tempos (e seus respectivos mapas de Lorenz).

A partir desses resultados é possível observar que o sistema em regime oscilatório é fortemente dependente das proporções entre o eletrólito de suporte e o álcool. Para baixas concentrações de álcool o sistema não apresenta janelas caóticas, porém a medida que se aumenta a quantidade de álcool instaura-se o caos e este, a altas concentração, é predominante durante o período em que o sistema passa oscilando.

\subsection{2 - INFLUÊNCIA DA DENSIDADE DE CORRENTE}

À medida que a concentração de EG aumenta observa-se maiores densidades de corrente no voltamograma, assim, da mesma forma que é importante um estudo da variação dos padrões com a concentração de EG, é importante um estudo da dependência dos padrões com a densidade de corrente aplicada ao sistema.

Como será discutido na próxima seção, a produção de intermediários de reação interfere de maneira capital no processo oscilatório e a difusão desses intermediários para o seio da solução deve ser considerada. A taxa com que esses intermediários são produzidos é proporcional à densidade de corrente, ainda que o processo de difusão das espécies para o seio 
da solução tenha uma dependência bem mais sutil com a taxa de transferência de elétrons na interface.

Quando maior a densidade de corrente maior é a taxa de produção de intermediários e, portanto, maior é a concentração dos mesmos na interface. Além disso, a quantidade de EG na interfase diminui com o aumento da densidade de corrente, uma vez que seu consumo será regido pela taxa de transferência de elétrons (que aumenta com o aumento da corrente) e sua reposição dependente exclusivamente da difusão de moléculas do seio para a interface.

A Figura 16 mostra a influência da densidade de corrente no processo oscilatório para uma concentração de $1 \mathrm{M}$ de $\mathrm{KOH}+0,4 \mathrm{M}$ de EG.

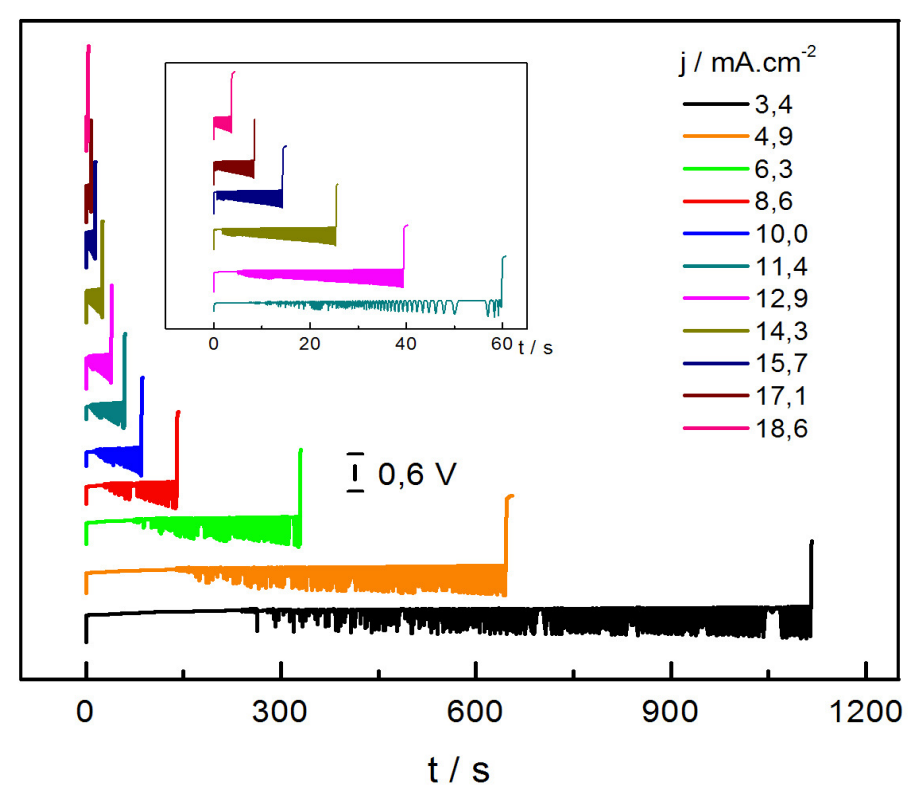

Figura 16 - Influência da densidade de corrente durante medidas de cronoamperometria. No detalhe as 5 últimas adições.

O sistema oscila até densidades de correntes próximas às obtidas em regime potenciodinâmico (voltametria cíclica) onde há contribuição da corrente capacitiva.

Assim como acontece com o aumento das concentrações dos intermediários, o aumento da densidade de corrente faz com que ambos, o período de indução e o tempo em 
que o sistema passa oscilando diminuam. No detalhe pode-se observar que a altas densidades de corrente o período de indução é praticamente zero, diferentemente do alcançado quando há adição dos intermediários. A Figura 17 apresenta a variação do tempo de indução em função do aumento de corrente.

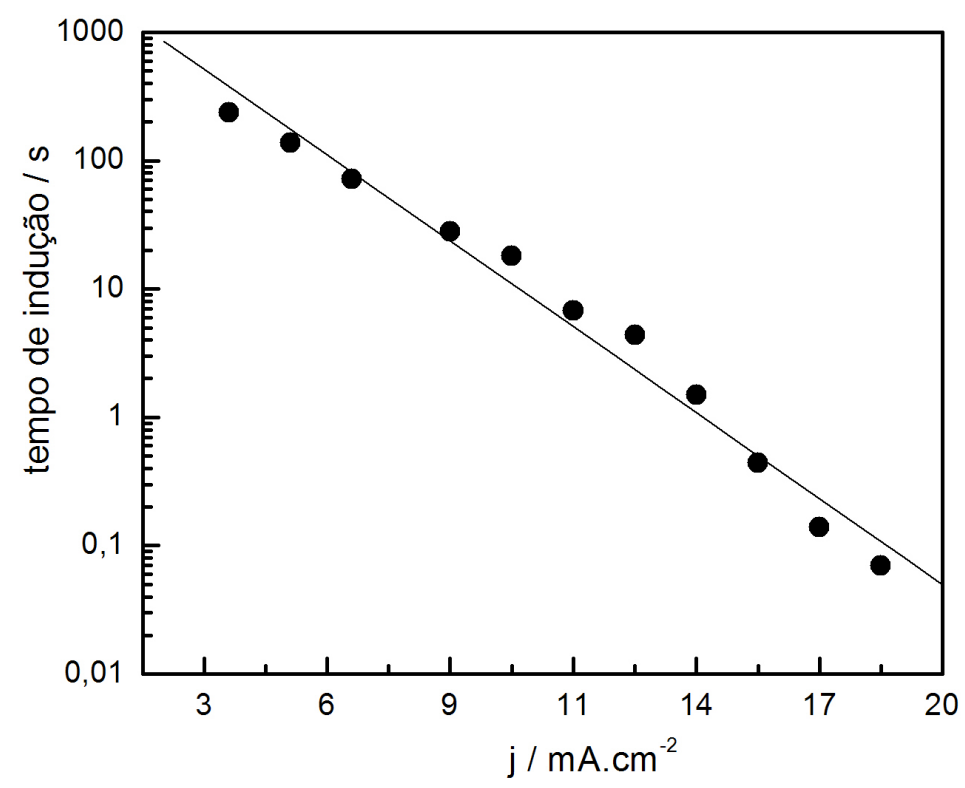

Figura 17 - Tempo de indução em função da densidade de corrente aplicada.

Os padrões de oscilação também são dependentes da densidade de corrente. Os padrões encontrados são semelhantes aos mostrados previamente nas Figuras 11 12, 14 e 15, de forma que apenas um resumo geral da dinâmica é ilustrado na Figura 18. 

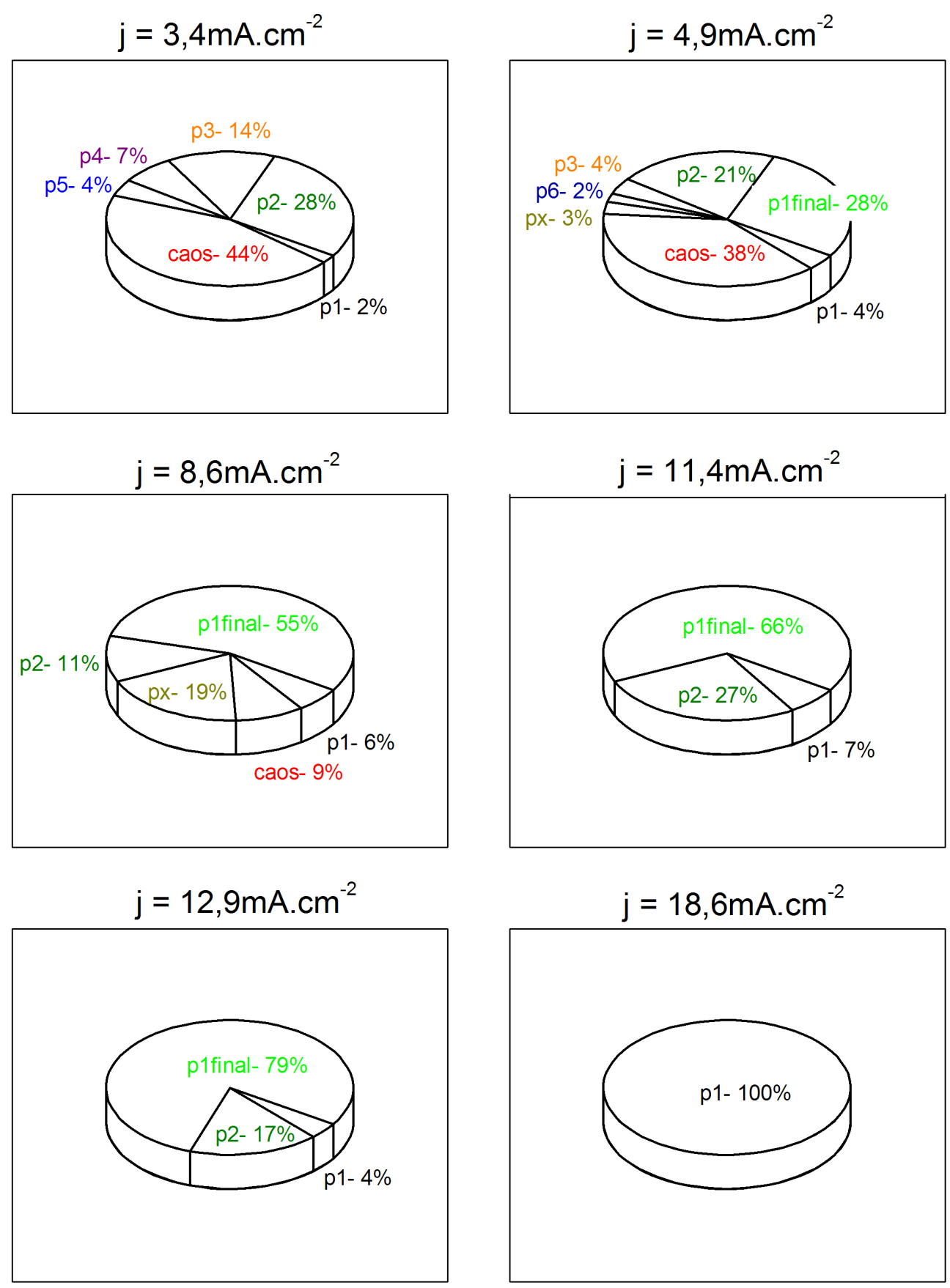

Figura 18 - Relação percentual dos padrões de oscilação sob regime galvanostático em diferentes correntes. $1 \mathrm{M} \mathrm{KOH} \mathrm{+} \mathrm{0,4M} \mathrm{EG.}$

À medida que a densidade de corrente é elevada o sistema apresenta padrões de menores ordens. Em baixas densidades de corrente o sistema o sistema apresenta uma grande diversidade de períodos, ressaltando que quase $50 \%$ do tempo oscilante é reservado às oscilações caóticas. Em contrapartida, quando a densidade de corrente é elevada em 
aproximadamente 6 vezes o sistema somente apresenta período 1. De modo geral observa-se que a morfologia das oscilações vai se tornando mais simples com o aumento da densidade de corrente como pode ser claramente notado na Figura 19 que resume essa discussão. Na figura o termo "p1 total" se refere à soma dos períodos 1 apresentados no início ou no final do regime oscilatório.

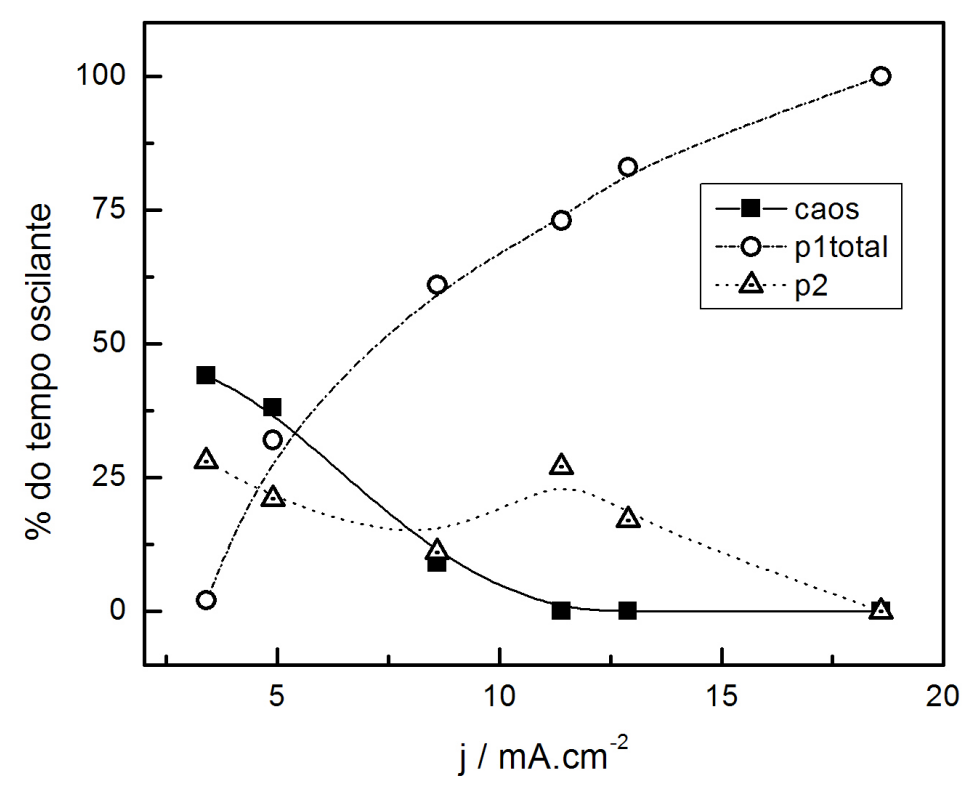

Figura 19 - Porcentagens dos padrões apresentados em função da corrente aplicada.

\subsection{3 - INFLUÊNCIA DOS INTERMEDIÁRIOS DE REAÇÃO}

As medidas acima foram realizadas a correntes constantes, e com uma temperatura ambiente praticamente constante durante o experimento $\left(25 \pm 1{ }^{0} \mathrm{C}\right)$, porém, observa-se que a partir de um determinado momento o sistema passa a oscilar e ocorre mudança nos padrões dessa oscilação. Tal comportamento parece estar relacionado à variação de um parâmetro não controlado como, por exemplo, fluxo de reagentes na solução através de convecção ou difusão 
ou produção de intermediário na interface. Esta última hipótese é de grande interesse, pois se a produção lenta de um certo intermediário induz a algum padrão específico, tal padrão pode ser utilizado para a identificação desses produtos em outros sistemas e isso permitiria intuir sobre por quais mecanismos a reação procede.

O inconveniente de se trabalhar nessa linha é exatamente conseguir desvendar com exatidão a natureza dos produtos em regime oscilatório, uma vez que a quantidade formada em alguns casos é bem pequena e existe um gradiente fazendo com que esses produtos se difundam para o seio da solução. Além do mais, o tempo em que o sistema apresenta determinado padrão é relativamente pequeno em relação ao tempo que se leva para realizar uma medida para quantificar esse produto por uma técnica como, por exemplo, FTIRS in situ de forma convencional. Mesmo que uma determinação mais precisa ainda não seja possível, pode-se estudar se a presença de um determinado intermediário influencia ou não regime oscilatório.

Se a eventual produção (e conseqüente acúmulo na interface) de intermediários de reação pode modificar a evolução do processo oscilatório, a adição desses intermediários ao sistema ocasionaria o mesmo efeito, porém, em um tempo menor. Seguindo esse raciocínio foram realizados experimentos em que quantidades de glicolaldeído (GA) e ácido glicólico (AG) foram adicionados no sistema contendo $1 \mathrm{M}$ de $\mathrm{KOH}$ e $0,4 \mathrm{M}$ de EG. Tais intermediários foram escolhidos por apresentarem baixo grau de oxidação em relação ao álcool, ou seja, o GA resulta da oxidação parcial (a aldeído) de apenas uma das hidroxilas do álcool com a passagem de dois elétrons, e o AG da oxidação do grupo aldeído a ácido carboxílico com a passagem de mais 2 elétrons sendo que estudos espectroeletroquímicos em regime potenciostático sugerem a formação desse ácido a partir da oxidação do EG [36]. As fórmulas estruturais desses compostos estão mostradas na Figura 3 sendo que o ácido glicólico em meio alcalino encontra-se como glicolato. 
Antes da adição de GA ao sistema, foi realizada uma medida de voltametria cíclica para observar o estado do sistema, a Figura 20 mostra o voltamograma do eletrólito de suporte (em preto) ampliado 50 vezes para poder observar os detalhes na escala usada para as demais medidas. Quando EG é adicionado (vermelho) observam-se os picos resultantes da oxidação do álcool (um pico na varredura do sentindo crescente de potencial e outro, de menor intensidade, na varredura oposta). A adição de GA não traz nenhum pico adicional, porém a intensidade dos picos relativos ao EG diminui consideravelmente, isto mostra que o GA atua na interface eletrodo/solução inibindo a reação de eletrooxidação.

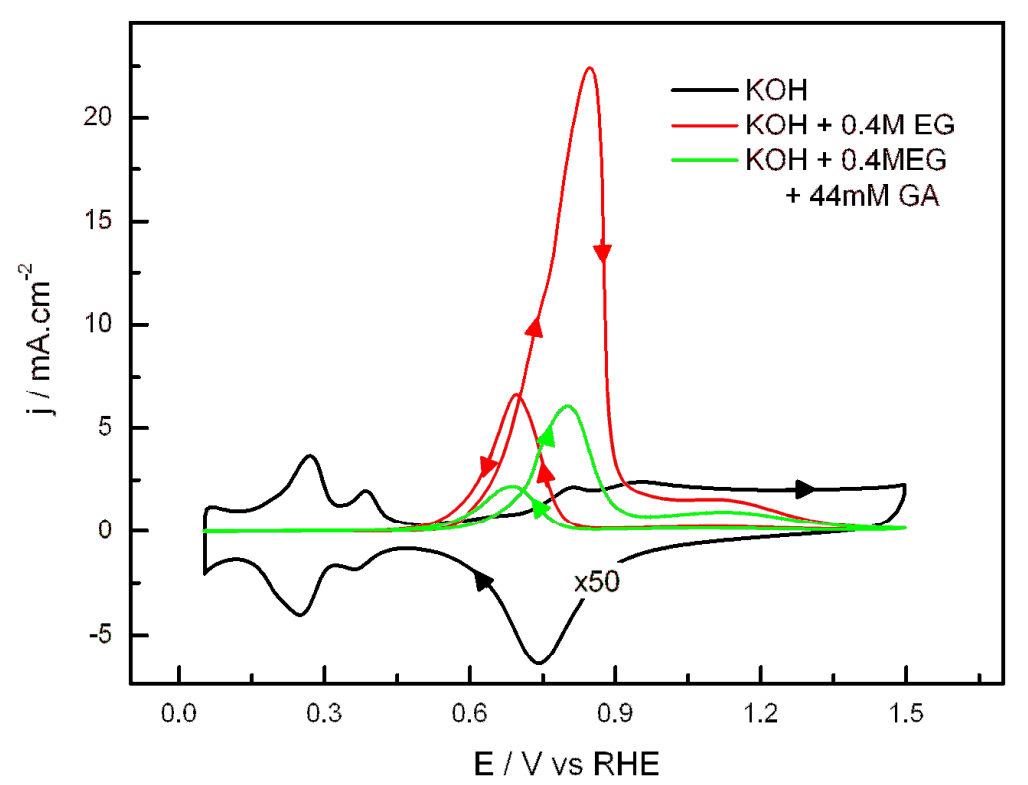

Figura 20 - Voltamograma cíclico a $0,05 \mathrm{~V} \cdot \mathrm{s}^{-1}$ em $1 \mathrm{M}$ de KOH (preto), após adição de 0,4 M de EG (vermelho) e após adição de $44 \mathrm{mM}$ de GA (verde).

Nos resultados mostrados na Figura 21, o sistema é mantido sob regime galvanostático com uma corrente de $3,4 \mathrm{~mA} . \mathrm{cm}^{-2}$. A curva em preto representa apenas o sistema com $1 \mathrm{M}$ de $\mathrm{KOH}$ e $0,4 \mathrm{M}$ de EG e as demais curvas representam a resposta quando quantidades de GA são adicionadas, mantendo-se as demais condições da curva em preto. 
Adição de uma pequena quantidade de GA na solução (da ordem de $\mu \mathrm{M}$ ) já representa um impacto considerável no que se diz respeito ao tempo de indução e no tempo em que o sistema passa oscilando. As adições subseqüentes vêm comprovar a constatação anterior.

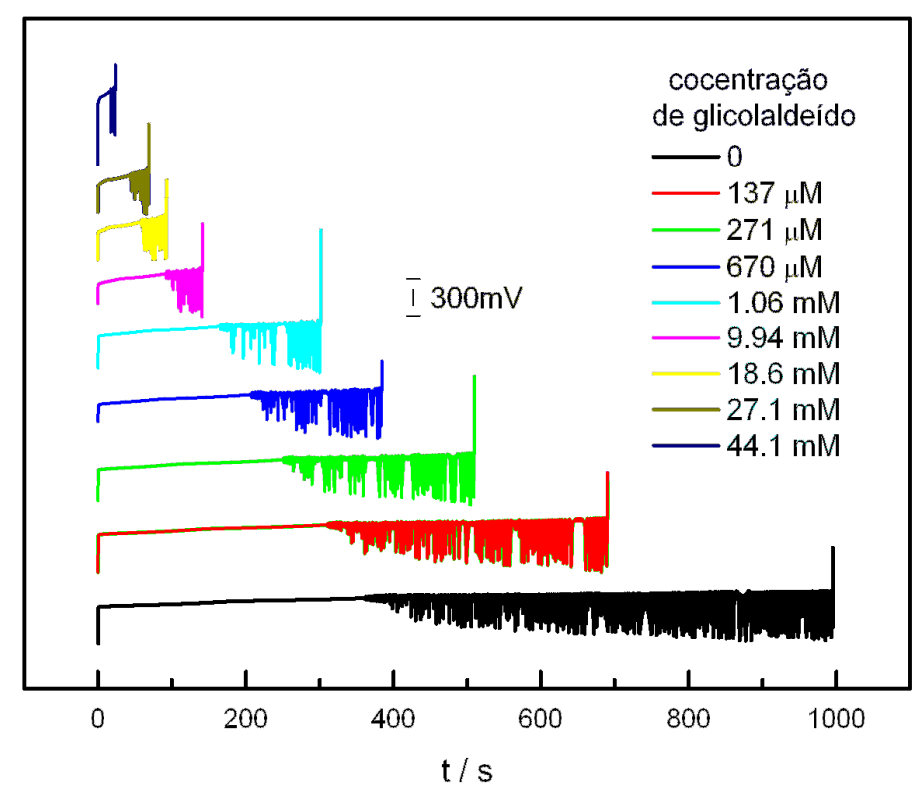

Figura 21 - Influência da quantidade de glicolaldeído durante medidas de cronoamperometria. $\mathrm{j}=3,4 \mathrm{~mA} . \mathrm{cm}^{-2}$

Seguindo a mesma linha de raciocínio adicionou-se ácido glícólico (AG) ao sistema contendo $1 \mathrm{M}$ de $\mathrm{KOH}$ e 0,4 M de EG. A Figura 22 mostra os voltamogramas cíclicos da Pt em $\mathrm{KOH}$, após a adição de EG, e após a adição de AG. Analogamente à adição de glicolaldeído, a presença do AG faz com que haja uma diminuição na corrente de oxidação e não é observado nenhum pico adicional no voltamograma. Uma importante distinção entre os dois casos é que a concentração de AG adicionada é aproximadamente 16 vezes maior que a de GA para que a corrente de oxidação diminua a 1/3 de seu valor original. 


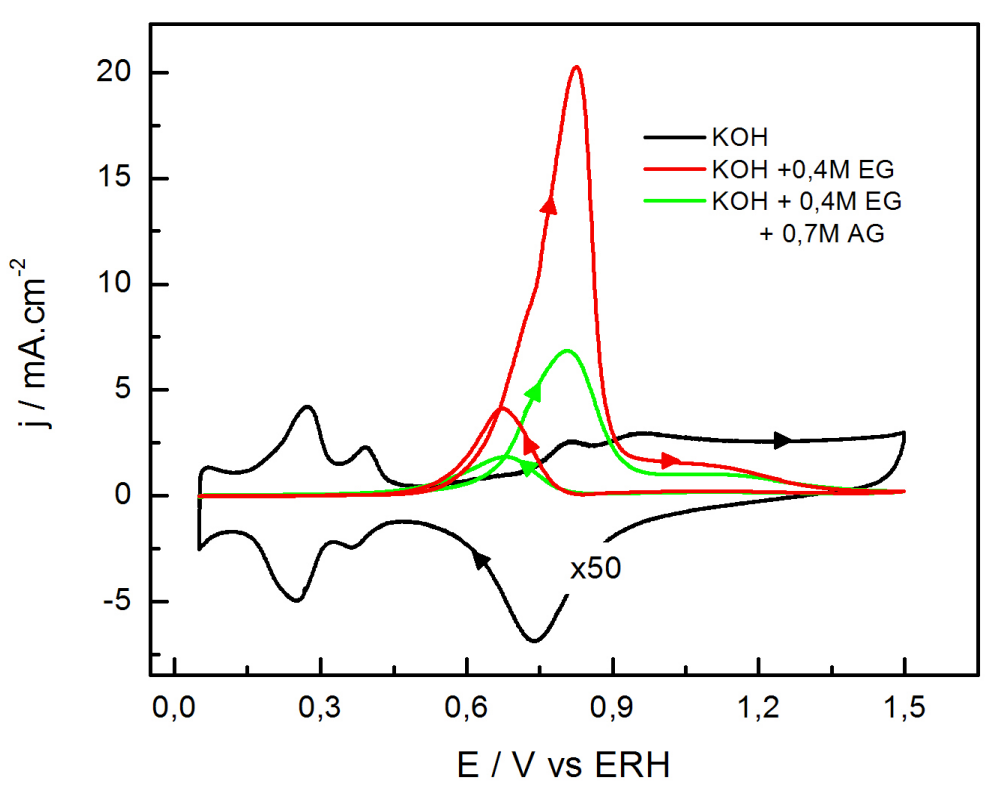

Figura 22 - Voltamograma cíclico a 0,05 V.s ${ }^{-1}$ em 1 M de $\mathrm{KOH}$ (preto), após adição de 0,4 M de EG (vermelho) e após adição de $0,7 \mathrm{M}$ de AG (verde).

A adição sistemática de pequenas quantidades de AG (Figura 23) também produz uma diminuição gradativa no tempo de indução e no tempo em que o sistema passa oscilando.

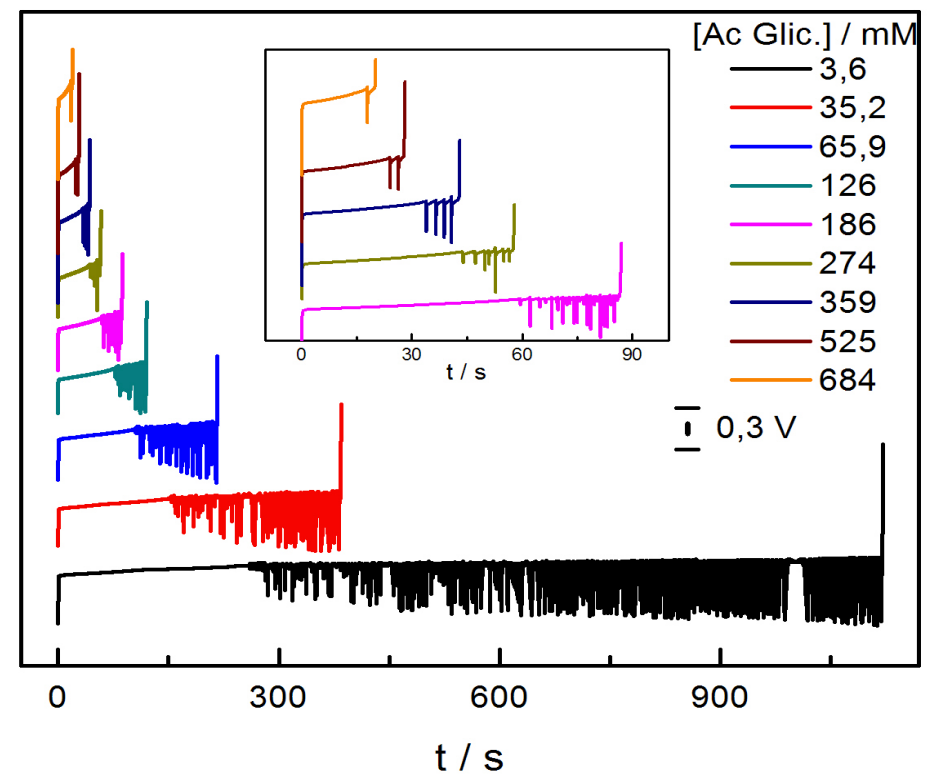

Figura 23 - Influência da quantidade de ácido glicólico durante medidas de cronoamperometria. $\mathrm{j}=3,4 \mathrm{~mA} \cdot \mathrm{cm}^{-2}$. No detalhe as 5 últimas adições. 
Estas concentrações não podem ser comparadas com as produzidas através da eletrooxidação do EG, uma vez que o sistema também está produzindo intermediários durante o processo de oxidação do álcool.

Nas Figuras 20 e 22 um fato que chamou a atenção foi a diminuição da densidade de corrente nos voltamogramas após a adição de glicolaldeído ou ácido glicólico. Para entender melhor tal processo realizou-se um experimento apenas com ácido glicólico em solução de $\mathrm{KOH}$ para verificar o comportamento do ácido sobre platina. Os resultados são mostrados na Figura 24.

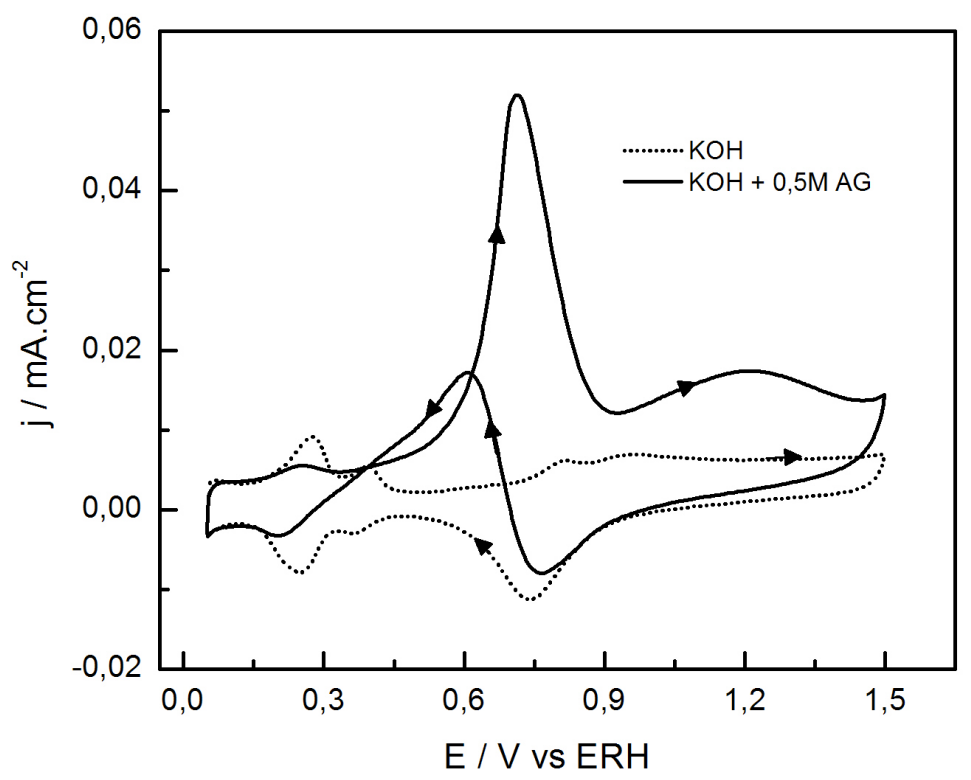

Figura 24 - Voltamograma cíclico a 0,05 V.s ${ }^{-1}$ em 1 M KOH (preto), após adição de 0,5 M de AG (vermelho).

Observa-se que o AG apresenta picos de oxidação na mesma região de potencial do EG tanto na varredura em sentido crescente quando decrescente de potencial. A presença de uma pequena corrente de redução por volta de $0,75 \mathrm{~V}$ mostra que há necessidade da redução parcial dos óxidos de Pt formados a altos potenciais para que o processo de oxidação do orgânico seja reativado. Outro fato digno de nota é a redução da região de dessorsão/oxidação 
de hidrogênio indicando a presença de intermediários de reação adsorvidos no eletrodo nessa região de potencial.

A comparação quantitativa da Figura 22 com a Figura 24 revela uma grande diferença entre os valores de densidade de corrente, sendo mais de $20 \mathrm{~mA} \cdot \mathrm{cm}^{-2}$ o máximo obtido com EG contra apenas $0,05 \mathrm{~mA} . \mathrm{cm}^{-2}$ apresentado pelo AG. Nessas medidas as concentrações de ambas as espécies eram equivalentes, evidenciando que a oxidação do AG é bem menos pronunciada.

Além das medidas de voltametria cíclica foram feitos estudos em condições potenciostáticas, sendo a faixa de potencial utilizada a mesma das amplitudes das oscilações, e analisando o comportamento da carga (através da integração da densidade de corrente após 1200 s de polarização) com o aumento da concentração de glicolaldeído no sistema.

A Figura 25 mostra as medidas de cronoamperometria realizadas a $0,8 \mathrm{~V}$ primeiramente em uma solução $1 \mathrm{M}$ de $\mathrm{KOH}+0,4 \mathrm{M}$ de $\mathrm{EG}$ e em seguida após sucessivas adições de AG.

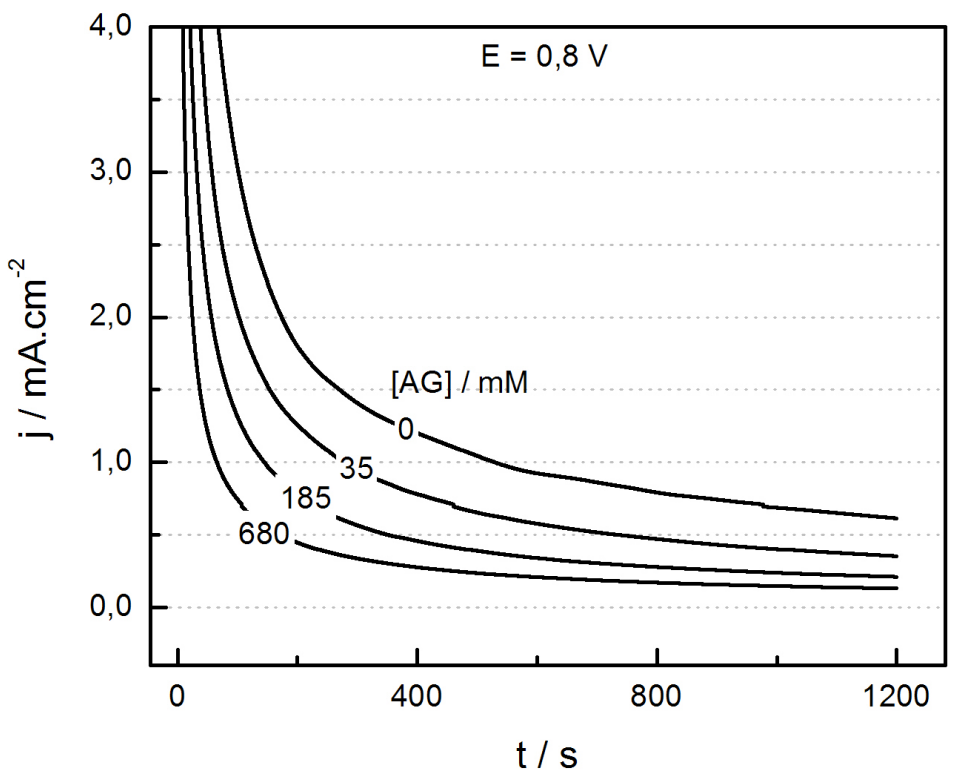

Figura 25 - Cronoamperometria a 0,8 V com várias adições de AG. A curva (0) corresponde ao sistema contendo $1 \mathrm{M}$ de $\mathrm{KOH}+0,4 \mathrm{M}$ de $\mathrm{EG}$. 
Observa-se que à medida que se aumenta a concentração de AG ocorre diminuição da densidade de corrente. Para comparação dessas variações nos diferentes potencias (foram realizadas medidas a $0,4,0,6$ e $0,8 \mathrm{~V}$ ) efetuou-se uma normalização das correntes. A normalização consiste na razão entre a carga obtida durante os 1200 s de polarização em cada uma das cronoamperometrias pela carga obtida na ausência do intermediário, isto é, com apenas $\mathrm{KOH}$ e EG, de forma que, na ausência de AG, o valor da carga normalizada $\left(\mathrm{q}_{\mathrm{N}}\right)$ será igual a 1 .

A Figura 26 mostra a carga normalizada em função da concentração de AG adicionado. As diferentes curvas representam os diferentes potenciais impostos ao sistema. Esta figura mostra claramente que ocorre diminuição da carga produzida nos 3 potenciais em que foram realizadas as medidas.

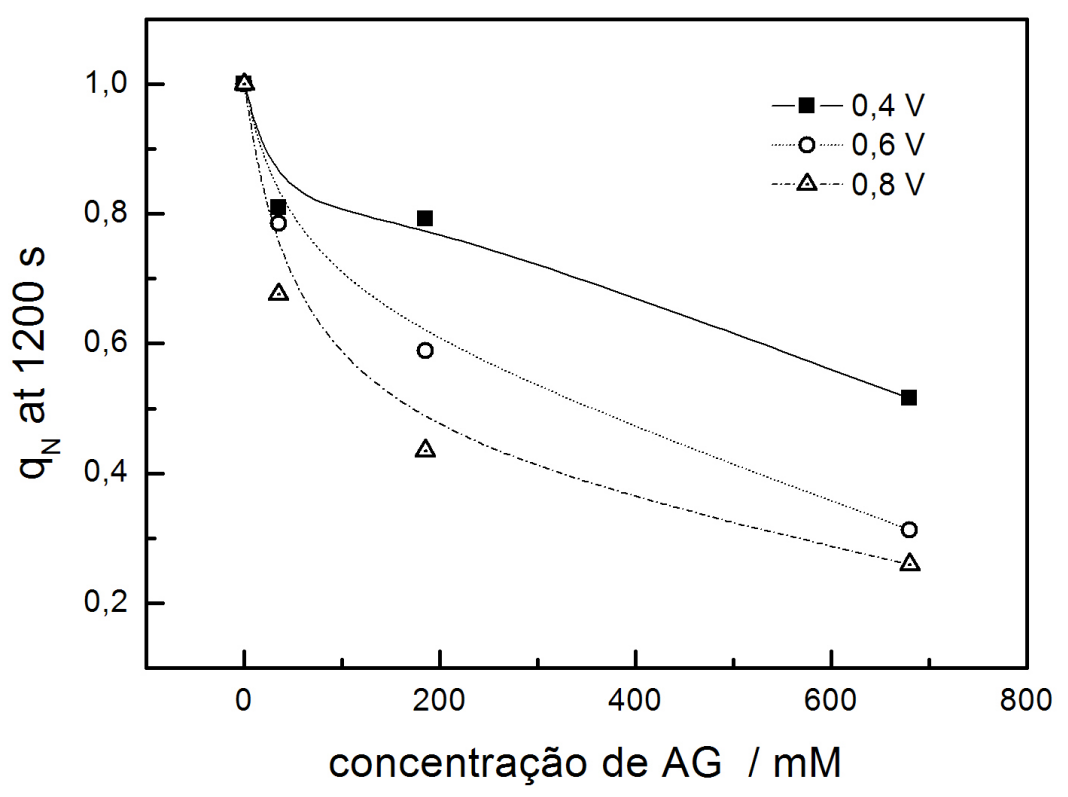

Figura 26 - Carga normalizada obtida sob regime potenciostático em função da concentração de AG.

Neste ponto é interessante buscar alguma relação entre as cargas obtidas em regime potenciostatico e a cargas produzidas sob regime galvanostático na parte linear (período de 
indução) ou durante todo o processo (incluindo o tempo que o sistema passa oscilando). Para a realização de tal comparação optou-se em trabalhar apenas com os resultados obtidos a $0,8 \mathrm{~V}$, pois o sistema, quando oscilando em regime galvanostático, passa mais tempo em potenciais dessa magnitude.

Analogamente à normalização realizada nas cargas sob regime potenciostático, as cargas produzidas a $3,4 \mathrm{~mA} . \mathrm{cm}^{-2}$ foram normalizadas pela carga produzida nessas condições sem a adição de AG. Calculou-se separadamente a carga produzida durante o período de indução $\left(\mathrm{q}_{\text {ind. }}\right)$ e a produzida durante todo o processo $\left(\mathrm{q}_{\text {total }}\right)$ que inclui o período de indução e o tempo que o sistema passa oscilando. A Figura 27 mostra a dependência dessas cargas normalizadas com a concentração de intermediário.

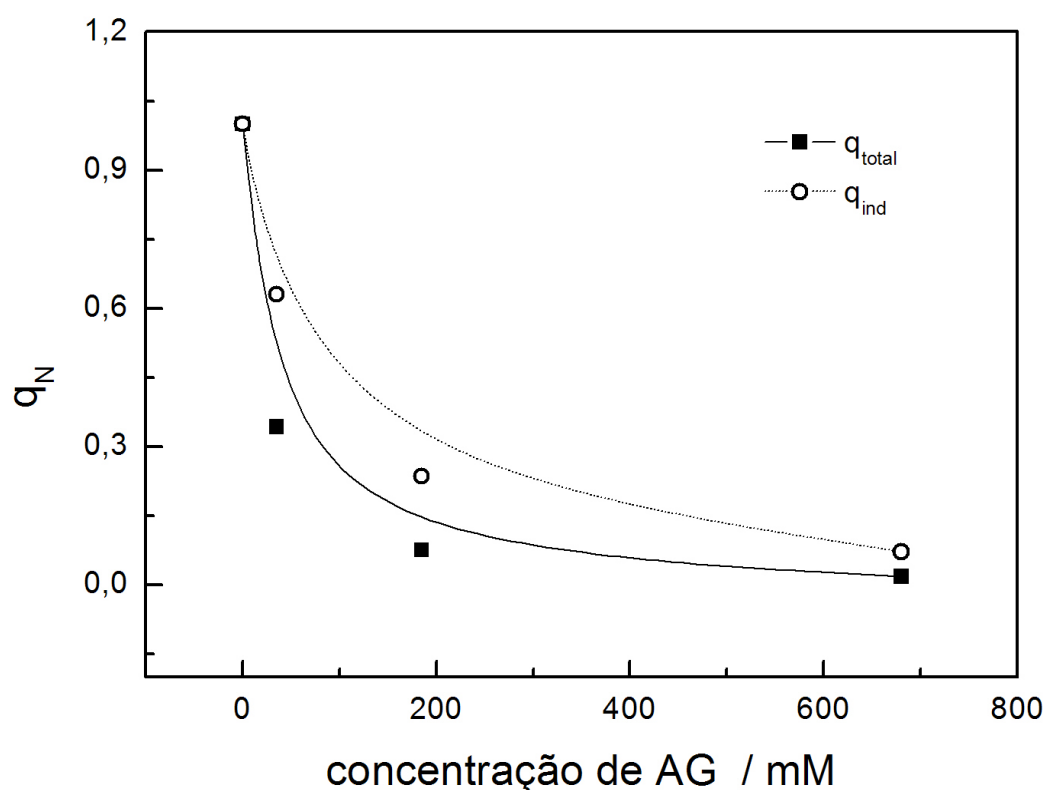

Figura 27 - Carga normalizada obtida em regime galvanostático considerando apenas o período de indução (círculos abertos) ou todo o processo (quadrados fechados) em função da concentração de AG. 
Essa figura é apenas uma outra representação da Figura 23 uma vez que em regime galvanostático, com correntes positivas, quanto maior o tempo maior será a carga, a diminuição da carga com o aumento de AG é a mesma tendência da Figura 23, em que o período de indução e o tempo que o sistema passa oscilando diminuem com a adição de AG. Outra informação dessa figura é a utilização da carga normalizada, pois esta pode ser comparada com a carga obtida em regime potenciostático. A comparação direta entre a carga produzida em regime galvanostático e potenciostático é mostrada na Figura 28.

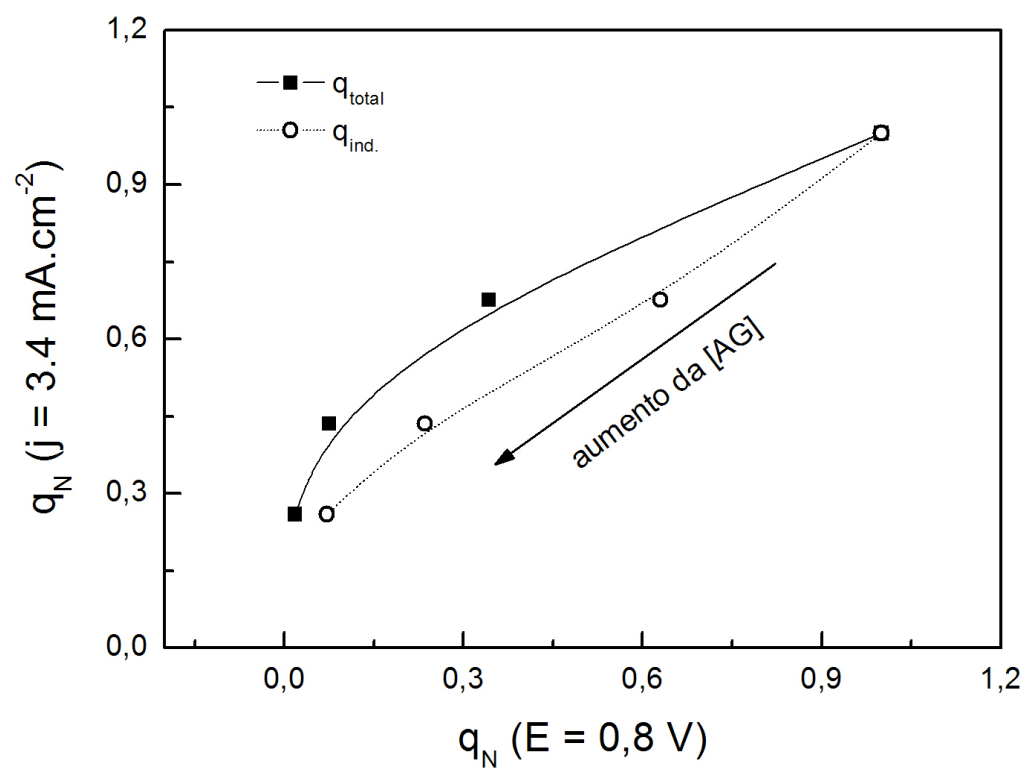

Figura 28 - Relação entre as cargas normalizadas obtidas sob regime galvanostático potenciostáticos em várias concentrações de AG.

Os pontos do eixo das abscissas da Figura 28 foram gerados pela carga produzida em regime potenciostático (através da integração da corrente após $1200 \mathrm{~s}$ de polarização a 0,8 V) nas diferentes concentrações de AG. Os pontos do eixo das ordenadas foram produzidos pela integração da corrente $\left(3,4 \mathrm{~mA} \cdot \mathrm{cm}^{-2}\right)$ de $\mathrm{t}=0$ até o início das oscilações ( $\mathrm{q}_{\text {ind. }}$ ) ou de t=0 até o 
tempo em que o potencial atinja valores maiores que $1,5 \mathrm{~V}\left(\mathrm{q}_{\mathrm{total}}\right)$. Os pares de pontos correspondem às cargas produzidas com a mesma concentração de AG no sistema.

Quando se considera as cargas obtidas somente durante período sob regime galvanostático observa-se que esta tem uma tendência linear com a carga produzida sob regime potenciostático. Nessas condições a presença do intermediário parece influenciar da mesma forma independente da variável mantida fixa (corrente ou potencial) e do regime em que a reação procede. Quando se considera o tempo em que o sistema oscila, a relação linear é perdida mostrando uma dependência muito maior da presença dos intermediários no processo oscilatório.

Descartando os aspectos quantitativos, em síntese pode-se afirmar que a presença dos intermediários GA e AG influencia o processo oscilatório. Em ambos os casos, quanto maior a quantidade dos intermediários na solução menor é o tempo de indução e menor o tempo que o sistema passa oscilando. A adição dos intermediários faz com que a densidade de corrente global diminua, provavelmente devido à adsorção desses intermediários no eletrodo e sua baixa taxa de oxidação bloqueando assim sítios de platina e impedindo a oxidação de moléculas de álcool.

\section{4 - ANÁlise Geral do Processo Oscilatório}

O mecanismo geral de oscilação descrito em termos de equações na introdução a esse tema parte de um modelo simples da interface eletrodo solução. Basicamente em determinadas condições quando o potencial do eletrodo $(\varphi)$ sofre uma perturbação local qualquer o sistema age através de um ciclo de retro-alimentação, fazendo com que a perturbação aumente rapidamente com o tempo. 
No entanto, para ocorrer oscilações, outra variável (Y) deve estar acoplada ao potencial do eletrodo. A mudança brusca de potencial do eletrodo faz com que o mesmo mude rapidamente suas características superficiais e permita outro tipo de reações, antes inativas a baixos potenciais. Assim pode-se determinar a variável Y como a concentração da espécie eletroativa ou a concentração de algum intermediário de reação. Quando $\varphi$ é alto o eletrodo passa a ser recoberto por óxidos, conseqüentemente altamente ativo para a oxidação do etileno glicol e intermediários, o que faz com que haja liberação de elétrons e conseqüente diminuição da corrente, como o sistema está sob regime galvanostático o potencial diminui.

Segundo a teoria da dinâmica não linear para um sistema "ativador inibidor" dará origem a oscilações se a escala de tempo em que o inibidor ocorre for menor que a do ativador [13]. Ou seja, no presente caso a taxa com que o $\varphi$ aumenta deve ser maior do que a as reações com Y se dão. A Figura 29 resume os ciclos de ativação e desativação de $\varphi$ e as equações que regem tais fenômenos. No caso de Y seu comportamento é descrito de forma genérica indicando que sua variação no tempo como uma função dela mesma e de $\varphi$. 


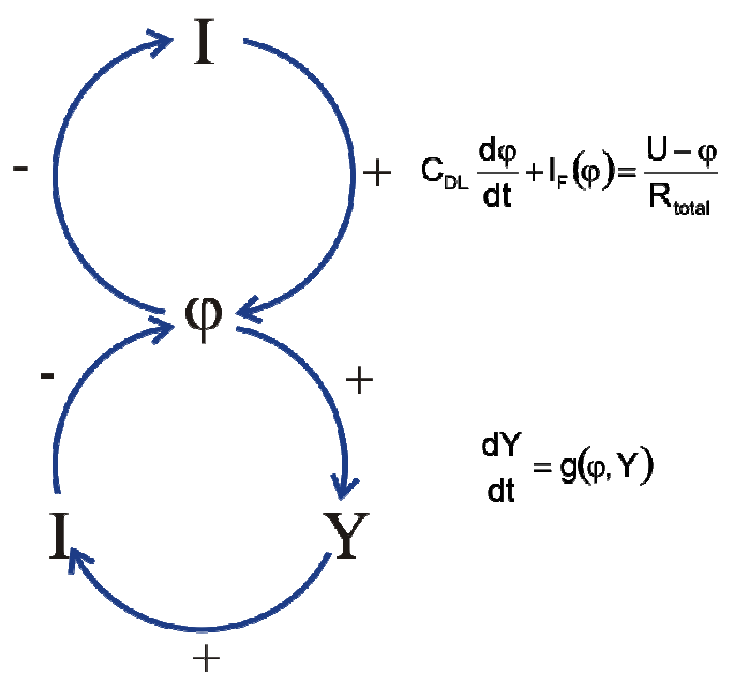

Figura 29 - Ilustração dos ciclos de retro-alimentação positivo e negativo após uma perturbação para um sistema com impedância faradaica negativa e uma espécie química Y.

Infelizmente estes ciclos somente descrevem o comportamento de oscilações muito simples como as harmônicas. Para descrever comportamentos mais complexos como períodos maiores que um chegando até em comportamentos caóticos há necessidade de se considerar, pelo menos, mais um grau de liberdade (no presente caso somente foram considerados $\varphi$ e Y) ou simplesmente outro ciclo de retro-alimentação.

Em geral, o terceiro grau de liberdade pode estar ligado ao transporte de massa de Y; alguma etapa química de formação de alguma espécie ou intermediário de reação na interface eletroquímica ou ainda a participação de algum íon do eletrólito suporte no processo uma vez que ocorre competição dessas espécies com as eletroquimicamente ativas por sítios livres do metal.

No presente trabalho observou-se o comportamento do regime oscilatório com a variação de vários parâmetros. Quando se variou a densidade de corrente observou-se que o regime oscilatório apresentava menores porcentagens de padrões caóticos e de altos períodos $(3,4,5$, etc). O aumento da densidade de corrente faz com que a taxa de consumo de espécies na interface seja maior, implicando na diminuição da quantidade de espécies eletroativas na 
interface, alem disso, ainda beneficia a formação de óxido no eletrodo pois a alta taxa de transferência de elétrons faz com que espécies oxigenadas formem óxidos superficiais na ausência de demais espécies eletroativas doadores de elétrons. Assim a variação da corrente é um parâmetro que influencia tanto os ciclos de retro-alimentação positivos quanto negativos.

O comportamento morfológico das oscilações em função da concentração mostra que quanto maior a concentração do álcool maior a porcentagem de tempo que o sistema apresenta caos. As variações do sistema em função da quantidade de álcool estão ligadas a modificações no ciclo de retro-alimentação negativo, que dependem da variável Y.

Porém não se pode classificar diretamente Y como sendo a quantidade de álcool na interface, pois em baixas concentrações a quantidade dessa espécie na interface deveria ser menor juntamente com seu transporte de massa. Tal fenômeno representaria mais um ciclo de retro-alimentação negativo e como conseqüência o terceiro grau de liberdade necessário para sistemas caóticos [13]. No entanto, o presente sistema apresenta exatamente comportamento oposto ao descrito na literatura para sistema com transporte de massa limitado, o que induz à idéia de que $\mathrm{Y}$ representa a produção de algumas espécies na interface que em altas concentrações de álcool poderia reagir entre si e gerar outros ciclos de retroalimentação negativo favorecendo os padrões caóticos.

A análise dos intermediários de reação mostra que sua adição faz com que o tempo de indução diminua bem como o tempo que o sistema passa oscilando. Como mostrado, a presença de intermediários acirra a competição por sítios livres do metal, diminuindo a taxa de reação da via de oxidação de EG. Esse feito influenciará nos ciclos de retro-alimentação negativo, pois mesmo que a concentração de EG seja alta a sua adsorção é desfavorecida por causa da competição por sítios além da possibilidade da criação de novos ciclos de retroalimentação uma vez que o intermediário pode seguir outras vias de oxidação. 


\section{5 - CONCLUSÕES}

Foram apresentados nesta dissertação alguns aspectos não-lineares da eletrooxidação de etileno glicol (EG) sobre $\mathrm{Pt}$ em $\mathrm{KOH}$. Oscilações em regime potenciostático e galvanostático foram observadas. As oscilações em modo galvanostático foram estudadas em duas concentrações distintas de $\mathrm{KOH}$ e em várias concentrações de EG. Em todos os casos, as oscilações estabelecem inicialmente de forma quase harmônica. Observou-se uma menor quantidade de padrões em baixa concentração de $\mathrm{KOH}$ e quando esta concentração foi aumentada em 10 vezes (mantendo a concentração de EG constante) o sistema apresenta uma grande diversidade de padrões tais como oscilações em modo misto, padrões de períodos 1,2 , 3 e 4. Mantendo-se a concentração de KOH fixa e variando-se a de EG observa-se que as janelas caóticas crescem com a concentração de EG.

A adição dos intermediários de reação faz tanto o período de indução como o tempo em que o sistema passa oscilando diminuam. Tal fenômeno pode estar ligado a competição por sítios livres de adsorção ou a interferência em ciclos retro-alimentativos que contenham esses intermediários.

O aumento da densidade da corrente também implica na diminuição do tempo de indução e do tempo em que o sistema passa oscilando, este parâmetro está conectado tanto ao ciclo de retro-alimentação positivo quanto ao(s) negativo(s). Finalmente, observou-se que quanto mais alta a corrente mais simples são os padrões. 


\section{6 - Perspectivas}

As análises realizadas no presente trabalho utilizaram técnicas simples devido ao "estado da arte" que se encontram as oscilações em sistemas com moléculas contendo 2 carbonos. Sistemas mais elaborados nos quais o controle dos parâmetros é mais rígido e a separação de variáveis como produção de intermediários, mapeamento in situ da superfície e o controle hidrodinâmico na interface certamente ajudariam na elucidação dos processos presentes na interface eletrodo/solução.

Para trabalhos posteriores, sugere-se trabalhar com eletrodos de Pt com vários fatores de rugosidade em sistema rotatório. Esta técnica, além do controle hidrodinâmico, quando utilizada em conjunto com um eletrodo do tipo disco anel possibilitaria a detecção de espécies formadas durante a medida.

Outro ponto muito interessante é a pouca informação, até o momento, sobre os aspectos não-lineares da eletrooxidação de etanol, uma busca na literatura indica apenas uma referência sobre esse tipo sistema e ainda de caráter meramente ilustrativo [29]. Uma investigação comparativa com o etanol nas mesmas condições em que o etileno glicol pode ser reveladora devido a similaridade entre as duas moléculas.

A espectroscopia de infravermelho in situ também é uma técnica que pode trazer importantes informações sobre as espécies formadas durante o processo oscilatório. Recentemente esta técnica foi utilizada em trabalhos do grupo durante a eletrooxidação de metanol e ácido fórmico em meio ácido. Os resultados iniciais mostram as diferenças da 
cobertura de $\mathrm{CO}_{\mathrm{ad}}$ durante o período de indução bem como o deslocamento da banda de $\mathrm{CO}$ durante a oscilação [*] e estão mostrados na Figura 30.
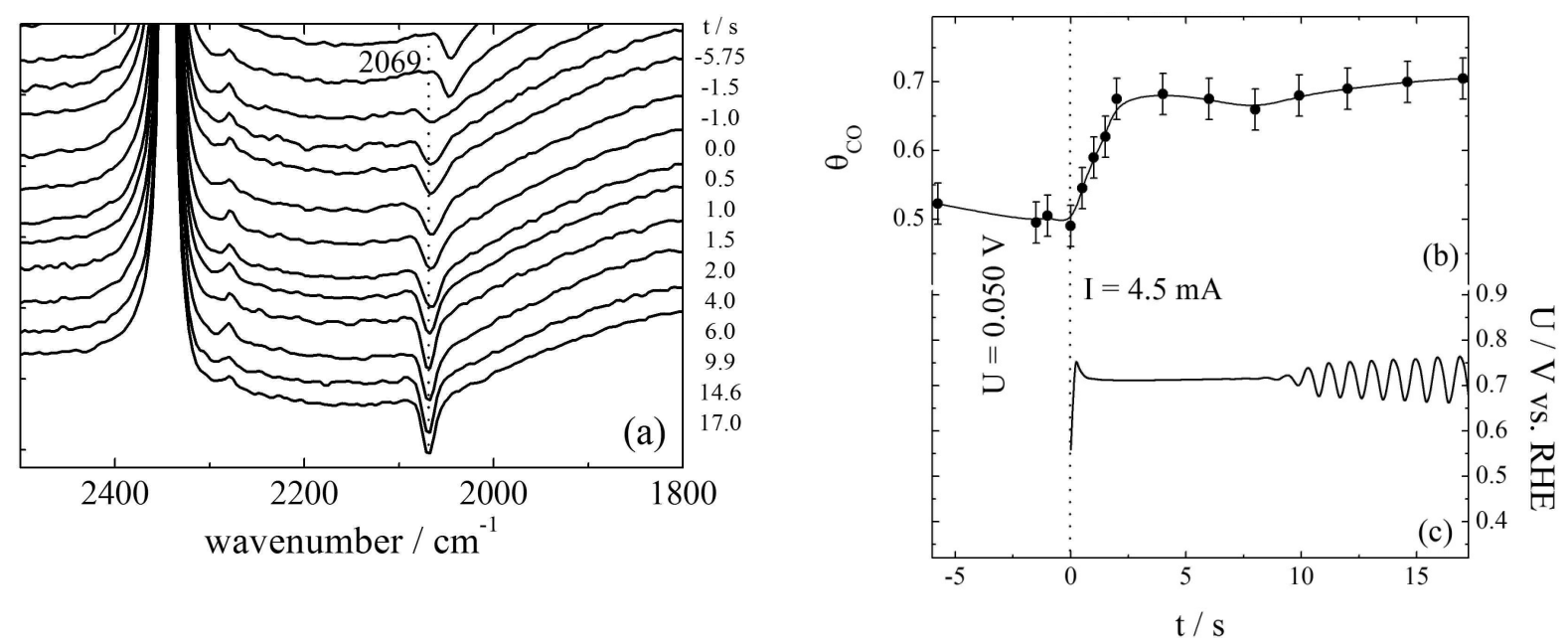

Figura 30 - (a) Espectros de FTIR coletados em função do tempo durante a eletrooxidação de metanol. (b) recobrimento de CO obtido através da integração da banda em $2069 \mathrm{~cm}^{-1}$ e (c) evolução do potencial no tempo, para $\mathrm{t}<0$ o eletrodo estava polarizado em $0,05 \mathrm{~V}$, para $\mathrm{t}>0$ uma corrente de $1,1 \mathrm{~mA} \cdot \mathrm{cm}^{-2}$ foi aplicada [*].

Finalmente, uma característica bastante interessante presente em praticamente todas as oscilações observadas durante a eletrooxidação de etileno glicol sobre platina e em meio alcalino está relacionada às altas frequiências das oscilações, ver por exemplo os valores mostrados na Tabela 1 para outros osciladores similares. Associada à riqueza dinâmica apresentada ao longo desta dissertação, tal característica coloca este oscilador na posição de um ótimo candidato a ser utilizado em estudos com configuração espacialmente estendida. $\mathrm{O}$ estudo do impacto das condições de acoplamento na dinâmica espaço-temporal utilizando osciladores pontuais desse tipo ainda não foi relatado na literatura.

[*] - MARTINS, A. L.; BATISTA, B.; SITTA, E.; VARELA, H. Oscillatory instabilities during the electrocatalytic oxidation of methanol on platinum, Journal of the Brazilian Chemical Society, 2007 - submetido. 


\section{6 - REFERÊNCIAS BIBLIOGRÁFICAS}

[1] NICOLIS, G.; PRIGOGINE, I. Exploring complexity: an introduction. New York: W.H. Freeman, 1989. 313 p.

[2] BALL, P. The self-made tapestry: pattern formation in nature. Oxford: Oxford University Press, 2001. 287 p.

[3] TAYLOR, A. F. Mechanism and phenomenology of an oscillating chemical reaction. Progress in Reaction Kinetics and Mechanism, v. 27, n. 4, p. 247-325, 2002.

[4] IMBIHL, R.; ERTL, G. Oscillatory kinetics in heterogeneous catalysis. Chemical Reviews, v. 95, n. 1, p. 697-733, 1995.

[5] HUDSON, J. L.; TSOTSIS, T. T. Electrochemical reaction dynamics: a review. Chemical Engineering Science, v. 49, n. 10, p. 1493-1572, 1994.

[6] KOPER, M. T. M. Oscillations and complex dynamical bifurcations in electrochemical systems. In: PRIGOGINE I; RICE, S. A. (Eds.). Advances in chemical physics. New York: Wiley, 1996. v. 92, p. 161-298.

[7] CHRISTOPH, J.; EISWIRTH, M. Theory of electrochemical pattern formation. Chaos, v. 12, n. 1, p. 215-230, 2002.

[8] KRISCHER, K. Principles of spatial and temporal pattern formation in electrochemical systems. In: BOCKRIS, J. O. M.; CONWAY, B. E. (Eds.). Modern aspects of electrochemistry. New York: Kluver Academic, 1999. v. 32, p.1-142.

[9] KOPER, M. T. M.; SLUYTERS, J. H. Electrochemical oscillators: their description through a mathematical model. Journal of Electroanalytical Chemistry, v. 303, n. 1-2, p. 73-94, 1991.

[10] STRASSER, P.; EISWIRTH, M.; KOPER, M. T. M. Mechanistic classification of electrochemical oscillators: an operational experimental strategy. Journal of Electroanalytical Chemistry, v. 478, n. 1-2, p. 50-66, 1999.

[11] VARELA, H.; KRISCHER, K. Nonlinear phenomena during electrochemical oxidation of hydrogen on platinum electrodes. Catalysis Today, v. 70, n. 1, p. 411-425, 2001.

[12] VARELA, Hamilton. Spatiotemporal pattern formation during electrochemical oxidation of hydrogen on platinum. 2003. 178 f. Tese (Doutorado), Freie Universität, Berlin, 2003. 
[13] KRISCHER, K.; VARELA, H. Oscillations and other dynamic instabilities. In: VIELSTICH, W.; LAMM, A.; GASTEIGER, H. (Eds.). Handbook of Fuel Cells: Fundamentals, Technology and Applications. Chichester: John Wiley, 2002. v. 2, p. 679-701.

[14] CAPON, A.; PARSONS, R. The oxidation of formic acid on noble metal electrodes: II. A comparison of the behaviour of pure electrodes. Journal of Electroanalytical Chemistry, v. 44, n. 2, p. 239-254, 1973.

[15] PLENGE, F.; VARELA, H.; LÜBKE, M.; KRISCHER, K. Quantitative modeling of the oscillatory electrooxidation of hydrogen on $\mathrm{Pt}$ in the presence of poisons. Zeitschrift für Physikalische Chemie, v. 217, n. 1, p. 365-381, 2003.

[16] BUCK, R. P.; GRIFFITH, L. R. Voltammetric and chronopotentiometric study of the anodic oxidation of methanol, formaldehyde, and formic acid. Journal of the Electrochemical Society, v. 109, p. 1005-1013, 1962.

[17] HUNGER, H. F. Participation of oxygen species in periodic anodic processes. Journal of the Electrochemical Society, v. 116 p. 1519-1523 1969.

[18] OKAMOTO, H.; TANAKA, N.; NAITO, M. Chaos in the oxidation of formaldehyde and/or methanol. Journal of Physical Chemistry A, v. 102, p.7343-7352, 1998.

[19] OKAMOTO, H.; TANAKA, N.; NAITO, M. Chaotic and periodic potential oscillations in formaldehyde oxidation. Journal of Physical Chemistry A, v.101, p. 8480-8488, 1997.

[20] KARANTONIS, A.; KOUTSAFTIS, D.; KOULOUMBI, N. Bistability, oscillations and bifurcations of the electrocatalytic oxidation of HCHO on Pt. Chemical Physics Letters, v. 422, p. 78-82, 2006.

[21] HACHKAR, M.; BEDEN, B.; LAMY, C. Oscillating electrocatalytic systems : Part I. Survey of systems involving the oxidation of organics and detailed electrochemical investigation of formaldehyde oxidation on rhodium electrodes. Journal of Electroanalytical Chemistry, v. 287, n. 1, p. 81-98, 1990.

[22] TIAN, M.; CONWAY, B. E. Phenomenology of oscillatory electro-oxidation of formic acid at Pd: role of surface oxide films studied by voltammetry, impedance spectroscopy and nanogravimetry. Journal of Electroanalytical Chemistry, v. 581, n. 2, p. 176-189, 2005.

[23] RASPEL, F.; EISWIRTH, M. Current oscillations in the electrochemical oxidation of formic acid at Pt single crystal surfaces. The Journal of Physical Chemistry, v. 98, n. 31, p. 7613-7618, 1994.

[24] STRASSER, P.; LÜBKER, M.; RASPEL, F.; EISWIRTH, M.; ERTL, G. Oscillatory instabilities during formic acid oxidation on $\mathrm{Pt}(100), \operatorname{Pt}(110)$ and $\mathrm{Pt}(111)$ under potentiostatic control. I. Experimental. Journal of Chemical Physics, v.107, n. 3, p.979-990, 1997.

[25] VIELSTICH, W.; PAGANIN, V. A.; LIMA, F. H. B.; TICIANELLI, E. A.

Nonelectrochemical pathway of methanol oxidation at a platinum-catalyzed oxygen gas 
diffusion electrode. Journal of the Electrochemical Society, v. 148, n.5, p. A502-A505, 2001.

[26] LEE, J.; EICKES, C.; EISWIRTH, M.; ERTL, G. Electrochemical oscillations in the methanol oxidation on Pt. Electrochimica Acta, v. 47, p. 2297-2301, 2002.

[27] KRAUSA, M.; VIELSTICH, W. Potential oscillations during methanol oxidation at Ptelectrodes Part 1: experimental conditions. Journal of Electroanalytical Chemistry, v. 399, p. 7-12, 1995.

[28] HUANG, W.; LI, Z. L.; PENG, Y. D.; CHEN, S.; ZHENG, J. F.; NIEL, Z. J. Oscillatory electrocatalytic oxidation of methanol on an $\mathrm{Ni}(\mathrm{OH})_{2}$ film electrode. Journal of Solid State Electrochemistry, v.9, p.284-289, 2005.

[29] ZHANG, L. J.; XIE, Q. J.; YAO, S. Z. EQCM study on the potential oscillations during galvanostatic oxidation of glucose, galactose and ethanol. Acta Physico-Chimica Sinica, v. 21, n. 9, p. 977-982, 2005.

[30] HORANYI, G.; INZELT, G.; SZETEY, E. Potential oscillations at platinum electrodes immersed into solutions of organic substances and redox systems. Acta Chimica Academiae Scientiarum Hungaricae, v. 97, n. 3, p. 299-311, 1978.

[31] SAMJESK, G.; OSAWA, M. Current oscillations during formic acid oxidation on a Pt electrode: insight into the mechanism by time-resolved IR spectroscopy. Angewandte Chemie International Edition, v. 44, p. 5694 -5698, 2005.

[32] LIMA, Roberto. Estudo da eletroxidação de etileno glicol em ligas de PtRu eletrodepositadas e em eletrodos de alta área superficial suportados em carbono. 2003. 51 f. Dissertação (Mestrado em Físico-Química). Instituto de Química de São Carlos, Universidade de São Paulo, São Carlos. 2003.

[33] LIMA, R. B.; PAGANIN, V.; IWASITA, T.; VIELSTICH, W. On the electrocatalysis of ethylene glycol oxidation. Electrochimica Acta, v. 49, p. 85-91, 2003.

[34] LIMA, Roberto. Estudo da eletroxidação de etileno glicol e seus produtos de oxidação parcial em eletrodos de Pt e PtRu. 2007. 85 f. Tese (Doutorado em FísicoQuímica). Instituto de Química de São Carlos, Universidade de São Paulo, São Carlos. 2007.

[35] HAUFFE,W.; HEITBAUM, J. The electrooxidation of ethylene glycol at platinum in potassium hydroxide. Electrochimica Acta, v.23, p.299-304, 1978.

[36] CHRISTENSEN, P. A.; HAMNETT, A. The oxidation of ethylene glycol at a platinumelectrode in acid and base - an in situ FTIR study. Journal of Electroanalytical Chemistry, v. 260, p. 347-359, 1989.

[37] IVES, D.; JANZ, G. Reference electrodes: theory and practice. New York: Academic Press, $1961.651 \mathrm{p}$. 
[38] HAMMAN, C. H.; HAMNETT, A.; VIELSTICH, W. Electrochemistry. Weinheim: Wiley-VHC, 2007. $531 \mathrm{p}$.

[39] TRASATTI, S.; PETRII, O. A. Real surface area measurements in electrochemistry. Pure and Applied Chemistry, v.63, n. 5, p. 711-734, 1991.

[40] SCHELL, M.; ALBAHADILY, F. N.; SAFAR, J.; XU, Y. H. Characterization of oscillatory states in the electrochemical oxidation of formaldehyde and formate formic acid Journal of Physical Chemistry, v.93, p. 4806-4810, 1989.

[41] BATISTA, E. A.; MALPASS, G. R. P.; MOTHEO, A. J.; IWASITA, T. New insight into the pathways of methanol oxidation. Electrochemistry Communications, v. 5, p.843-846, 2003. 